\title{
Los efectos de la invalidez en la Ley de Contratos del Sector Público
}

\author{
Silvia Díez Sastre (España) \\ Universidad Autónoma de Madrid \\ silvia.diez@uam.es
}

\section{NOTA BIOGRÁFICA}

Silvia Díez Sastre es Profesora Contratada Doctora de Derecho Administrativo en la Universidad Autónoma de Madrid. Es directora del Centro de Investigación sobre la Justicia Administrativa y del Máster en Contratación Pública Local del Instituto de Derecho Local de la misma Universidad. Sus líneas de investigación actuales se centran en la contratación pública, la justicia administrativa, el Derecho local y la metodología jurídica.

\section{RESUMEN}

El fenómeno de la invalidez plantea numerosos interrogantes. De entre todos ellos, este trabajo analiza los efectos de la invalidez en relación con los distintos mecanismos de revisión de las decisiones contractuales en el marco de la nueva Ley 9/2017, de 8 de noviembre, de Contratos del Sector Público (LCSP). Para ello, parte de una comprensión de la invalidez como el resultado de un juicio de ajuste de un acto al ordenamiento jurídico. Asimismo, entiende que no hay correlación entre la gravedad del vicio de invalidez -nulo o anulable- y el tipo de ineficacia que se predica en el caso concreto -ineficacia ex tunc o ineficacia ex nunc-. A partir de ahí, se analizan reacciones frente a la invalidez como la restitución de la legalidad, el resarcimiento, la retroacción de actuaciones, la cancelación del procedimiento o el mantenimiento del contrato ilegal.

\section{PALABRAS CLAVE}

Contratos públicos; invalidez; restitución; resarcimiento; retroacción de actuaciones.

\begin{abstract}
The legal concept of invalidity poses many problems. Among all of them, this paper tackles the consequences stemming from invalidity according to the new Act on Public Contracts (Act 9/2017, November 8). With this aim, invalidity is construed as the result of deviation from legal requirements. Furthermore it is argued that there is no correlation between the kind of invalidity - nullity or voidability-, and the consequences deriving from it -ex tunc or ex nunc ineffectiveness-. From this perspective, different results of invalidity are analyzed, such as restoration of the prior legal situation, damages, reversal of proceedings, cancellation of proceedings and the continuation of the null contract.
\end{abstract}

\section{KEYWORDS}

Public contracts; invalidity; restoration; damages; reversal of the proceedings.

\section{SUMARIO}

I. PLANTEAMIENTO. II. LAS PREVISIONES DEL DERECHO POSITIVO. 1. LA REGULACIÓN DE LOS EFECTOS DE LA INVALIDEZ. 2. EL MOMENTO EN QUE TIENEN LUGAR LOS EFECTOS DE LA INVALIDEZ. III. LOS TIPOS DE EFECTOS DE LA INVALIDEZ. 1. LOS FUNDAMENTOS DE LOS EFECTOS DE LA INVALIDEZ. 1.1. La teoría del control de la discrecionalidad. 1.2. La tutela de las posiciones 
jurídico-subjetivas de los particulares. 1.3. Garantía de funcionamiento del mercado y del interés público en el contrato. 2. EL RESTABLECIMIENTO DE LA LEGALIDAD. 2.1. La anulación. 2.2. La retroacción de actuaciones. 2.3. La condena a hacer a la Administración. 2.4. La cancelación de la licitación. 2.5. La liquidación del contrato. 2.6. La garantía de la continuidad del servicio. 3. EL RESARCIMIENTO DE DAÑOS Y PERJUICIOS. 3.1. Los daños causados al licitador. 3.2. En especial, la flexibilización de los requisitos ligados al deber resarcitorio. 3.3. Los daños causados al contratista. IV. PROBLEMAS PRÁCTICOS. 1. LOS PRONUNCIAMIENTOS DE IMPOSIBLE EJECUCIÓN. 2. LA FALTA DE CAPACIDAD DIRECTIVA DE LA CONDUCTA ADMINISTRATIVA. V. CONCLUSIONES: EL DERECHO ES EFICAZ CUANDO SE APLICA A TIEMPO. BIBLIOGRAFÍA.

\section{PLANTEAMIENTO ${ }^{1}$}

El fenómeno de la invalidez plantea numerosos interrogantes referidos, fundamentalmente, a la definición del concepto de invalidez, la determinación normativa de los motivos que están asociados a ella, los procedimientos orientados a su declaración y los efectos que se derivan de los actos inválidos. Este trabajo solo analiza los efectos de la invalidez en relación con los distintos mecanismos de revisión de las decisiones contractuales en el marco de la nueva Ley 9/2017, de 8 de noviembre, de Contratos del Sector Público (LCSP). Para ello, parte de una comprensión de la invalidez como el resultado de un juicio de ajuste de un acto al ordenamiento jurídico. Es un concepto que designa una cualidad que puede predicarse de una actuación administrativa. Se explica en un contexto de ajuste entre la realidad y la norma. Desde esa perspectiva, un acto es válido "cuando es conforme con el ordenamiento jurídico» ${ }^{2}$. Puede afirmarse entonces que la validez en sentido estricto es la conformidad (jurídicamente relevante) a las normas procedimentales o sustantivas para la producción de una actuación jurídica ${ }^{3}$. La validez se vincula, así, con «la satisfacción de las condiciones para el correcto y exitoso ejercicio de una potestad $»^{4}$.

Ahora bien, ¿qué sucede en el plano de los efectos cuando un acto es inválido? Habitualmente se parte de una separación entre el plano teórico-jurídico y el plano de los hechos que impide observar el fenómeno de la invalidez en toda su extensión ${ }^{5}$. Se afirma que un acto inválido es ineficaz. Sin embargo, es evidente que la mayoría de los actos inválidos producen efectos -los produjeron antes de que se declarara la invalidez-. Es más, en muchas ocasiones, el legislador se muestra a favor de mantener los efectos derivados de los actos inválidos. Gran parte de la doctrina, influida por algunas construcciones civilistas, afirma que la nulidad produce efectos «ex tunc», mientras que la anulabilidad desplegaría efectos «ex nunc» ${ }^{6}$. Sin embargo, esta distinción no puede constatarse en la realidad. Los conceptos de invalidez e ineficacia son independientes ${ }^{7}$. Y no hay correlación entre la gravedad del vicio de invalidez - nulo o anulable- y el tipo de ineficacia que se predica en el caso concreto -ineficacia ex tunc o ineficacia ex nunc-. Ni la hay en el Derecho positivo, ni la hay en la realidad. Esta afirmación se pone especialmente en evidencia en el ámbito de la contratación pública.

Las particularidades que plantea este sector desde el punto de vista de los efectos de la invalidez pueden concentrarse en torno a dos ejes: por un lado, se trata de un procedimiento de reparto de recursos escasos, en el que las relaciones entre la Administración y los particulares adquiere un cierto grado de complejidad; por otro lado, se trata de un ámbito fuertemente europeizado especialmente en relación con los sistemas de revisión y de control de la invalidez. Seguidamente se desarrollan brevemente cada uno de ellos:

a) El procedimiento de adjudicación de contratos públicos se encuadra en un tipo procedimental específico, de carácter competitivo, que articula intereses en pugna por el reparto de un bien escaso como son los contratos públicos ${ }^{8}$. Esto significa que la declaración de invalidez de un acto dictado en ese procedimiento

1 Este trabajo tiene su origen en la invitación de los profesores Santiago Muñoz Machado y Mariano López Benítez a participar en la edición de 2018 del Seminario sobre la Reforma del Estado, que se celebró en la sede del INAP en Madrid el 10 de octubre. Parte de las ideas que se recogen en este trabajo se contiene en las Actas del XII Congreso de la Asociación Española de Profesores de Derecho Administrativo, celebrado en La Laguna los días 3 y 4 de febrero de 2017, publicadas por el INAP ese mismo año.

2 A. GALLEGO ANABITARTE y Á. MENÉNDEZ REXACH (2001: 195).

3 J. L. PÉREZ TRIVIÑO (1999: 263); A. NIETO (1994: 10-11); M. R. ALONSO IBÁÑEZ (2017: 29).

4 N. MCCORMICK (2011: 207).

5 J. GARCÍA LUENGO (2002: 257)

6 Da cuenta de esta doctrina, M. BELADIEZ ROJO (1994: 62).

7 M. R. ALONSO IBÁÑEZ (2017: 31).

8 Sobre las particularidades del régimen jurídico de este tipo de actividad con carácter general, L. ARROYO JIMÉNEZ y D. UTRILLA (dirs.) (2015: passim); N. MALAVIYA (2009: 253). 
puede afectar a varios interesados; es más, puede llegar a proyectarse sobre el contrato celebrado entre la Administración -en sentido amplio- y el contratista. De modo que la invalidez de un acto puede desencadenar al mismo tiempo un beneficio para uno o varios particulares y un perjuicio para otros; a lo que se suma la dificultad de reponer las cosas al estado anterior a la invalidez cuando la ejecución del contrato ya está avanzada o, incluso, consumada. Por otro lado, la Administración puede requerir las prestaciones que son objeto de un contrato inválido, de modo que, en ocasiones, el interés público en el mantenimiento del contrato podrá primar sobre el deber de restablecer la legalidad, eliminando los actos de un contrato inválido. Como puede apreciarse, la articulación del prisma de intereses en juego en el ámbito de la contratación plantea un reto en el análisis de los efectos de la invalidez.

b) A las particularidades de la contratación pública como vía de reparto de recursos escasos, hay que sumar, asimismo, el intenso grado de europeización de los mecanismos de recurso que se ponen a disposición de los particulares. El Derecho europeo exige a los Estados miembros el establecimiento de mecanismos de impugnación de las actuaciones contrarias a las normas europeas de contratación pública. Esos mecanismos han de ser verdaderamente rápidos y eficaces, actuando en la fase en que las infracciones aún pueden corregirse (Directiva 89/665/CEE). Mediante el diseño de los procedimientos de adjudicación en consonancia con los procedimientos de recurso, el Derecho europeo consigue condicionar los efectos derivados de la invalidez. Incluso, establece mecanismos de sanción al órgano de contratación que ha producido el acto inválido, en determinadas circunstancias. Esta regulación aporta una visión novedosa para el Derecho español. Los efectos de la invalidez no se consideran una consecuencia de la aplicación de una teoría más o menos desarrollada al respecto. Por el contrario, se analizan los efectos que han de producirse en la práctica para lograr consecuencias concretas como, por ejemplo, evitar que se celebre el contrato antes de que se haya podido impugnar por las vías adecuadas o conseguir que el órgano que dicta un acto inválido experimente algún perjuicio de esa conducta. Esta perspectiva puede ser muy útil, y no solo en el ámbito de la contratación, para abordar el fenómeno de la invalidez como un mecanismo dinámico y no como un concepto dogmático estático. De esa manera se pueden diseñar procedimientos y normas que verdaderamente contribuyan a eliminar los actos inválidos del ordenamiento jurídico, garanticen la tutela de los particulares y, además, generen incentivos en la Administración para actuar conforme a Derecho.

Sobre estos presupuestos, a continuación, se analizan los efectos de la invalidez en la contratación pública. En primer lugar, se exponen las directrices del Derecho positivo en torno a los efectos de la invalidez en materia de contratación pública. Seguidamente se hace una propuesta de ordenación de los distintos efectos de la invalidez en torno a dos ejes: restablecimiento de la legalidad y resarcimiento de daños y perjuicios. En tercer lugar, se hace alusión a algunos problemas prácticos. Finalmente, se formulan unas breves conclusiones finales.

\section{LAS PREVISIONES DEL DERECHO POSITIVO}

\section{La regulación de los efectos de la invalidez}

Al igual que sus antecesoras ${ }^{9}$, la normativa vigente en materia de contratación pública contiene una serie de reglas específicas sobre las causas de invalidez de los contratos públicos - de nulidad y anulabilidad de Derecho Administrativo y de Derecho civil- y los efectos que derivan de ellas (arts. 38 y ss. LCSP). Estas reglas se recogen en el Capítulo IV, del Título I del Libro I de la Ley, titulado «régimen de la invalidez». En la nueva LCSP, el artículo 42 se dedica a los efectos de la declaración de nulidad y los efectos en supuestos de anulabilidad. El artículo 35 TRLCSP solo se refería a los efectos de la declaración de nulidad. Podría parecer, a primera vista, que el legislador ha pretendido diferenciar entre los efectos que se derivan de actos viciados de nulidad y de anulabilidad. Sin embargo, el contenido del precepto es prácticamente idéntico en ambas leyes:

«1. La declaración de nulidad de los actos preparatorios del contrato o de la adjudicación, cuando sea firme, llevará en todo caso consigo la del mismo contrato, que entrará en fase

\footnotetext{
${ }^{9}$ Artículo 35 TRLCSP (Real Decreto Legislativo 3/2011, de 14 de noviembre, por el que se aprueba el Texto Refundido de la Ley de Contratos del Sector Público); art. 35 LCSP de 2007 (Ley 30/2007, de 30 de octubre, de Contratos del Sector Público), artículo 65 TRLCAP (Real Decreto Legislativo 2/2000, de 16 de junio, por el que se aprueba el Texto Refundido de la Ley de Contratos de las Administraciones Públicas); y artículo 66 LCAP (Ley 13/1995, de 18 de mayo, de Contratos de las Administraciones Públicas).
} 
de liquidación, debiendo restituirse las partes recíprocamente las cosas que hubiesen recibido en virtud del mismo y si esto no fuese posible se devolverá su valor. La parte que resulte culpable deberá indemnizar a la contraria de los daños y perjuicios que haya sufrido.

2. La nulidad de los actos que no sean preparatorios solo afectará a estos y a sus consecuencias.

3. Si la declaración administrativa de nulidad de un contrato produjese un grave trastorno al servicio público, podrá disponerse en el mismo acuerdo la continuación de los efectos de aquél y bajo sus mismas cláusulas, hasta que se adopten las medidas urgentes para evitar el perjuicio (...)».

A la vista está que el legislador no distingue entre el grado de invalidez en el que incurría el acto o el contrato que es objeto de la declaración de nulidad. Sí diferencia, en cambio, en torno al tipo de acto inválido. Si se trata de un acto precontractual, la invalidez se contagia al contrato que se haya podido celebrar con posterioridad. Si, por el contrario, el acto no es preparatorio, de lo que hay que deducir que el legislador se refiere a actos en la fase de ejecución del contrato, entonces, la invalidez solo afecta a esos actos y sus consecuencias.

En relación con los efectos concretos que se anudan a la declaración de nulidad, el legislador solo regula los referidos al contrato inválido. La primera reacción frente a la invalidez es que el contrato entre en fase de liquidación. Como consecuencia directa, las partes han de devolverse las cosas recíprocamente, esto es, las prestaciones acordadas. Pero como es habitual que no sea posible devolver la prestación ya realizada -ya sea una obra, un servicio o los bienes suministrados $-{ }^{10}$, el legislador establece que, cuando no sea posible la devolución, las partes deben devolverse el valor. En la práctica, esto significará que el contratista que ha ejecutado todo el contrato o parte del contrato, debe recibir la contraprestación correspondiente por los trabajos realizados. Además, si se producen daños entre las partes, la culpable debe indemnizarlos. De manera que habrá que atender a la responsabilidad de cada parte en el vicio de invalidez. Así pues, los efectos de la nulidad de los actos producidos en el marco del procedimiento de adjudicación del contrato se consideran relevantes en la medida en que contagian al contrato celebrado con posterioridad ${ }^{11}$. Los efectos previstos se proyectan sobre la relación jurídica contractual entablada entre la Administración y el contratista. No se tienen en cuenta, con carácter general, los efectos o consecuencias que tiene la nulidad de esos actos más allá de la relación contractual.

No obstante, hay que destacar que el legislador sí apunta a la posibilidad de que el interés público module los posibles efectos de la invalidez de un contrato inválido. Para que se produzca ese efecto deben producirse graves trastornos al servicio público. Además, el mantenimiento del contrato inválido debe limitarse al tiempo necesario para adoptar medidas urgentes que remedien la situación. Sobre el alcance de esta regulación y su compatibilidad con el Derecho europeo se volverá más adelante, cuando se analice el mantenimiento de los efectos del contrato como una posible consecuencia de la invalidez.

Hasta aquí puede apreciarse cómo la regulación contenida en el actual artículo 42.1 LCSP estaba pensada para el sistema tradicional de revisión de las decisiones contractuales, mediante recursos administrativos, recursos contencioso-administrativos y revisiones de oficio. Ya se ha señalado que es un precepto que ha ido pasando de unas leyes a otras sin apenas modificaciones. Cuando se redactó esta norma, el legislador se centraba en los efectos vinculados al contrato inválido porque una posible declaración de invalidez de un acto preparatorio o del acto de adjudicación se produciría prácticamente con seguridad, cuando el contrato se hubiera celebrado y se estuviera ejecutando. De hecho, era habitual que el contrato ya estuviese ejecutado.

En este contexto, los sistemas de revisión apenas se empleaban por los candidatos y licitadores contra actos precontractuales. La litigiosidad en torno a la adjudicación de contratos públicos era meramente testimonial. Y no cabe presumir que ello se debiera a la especial corrección de los procedimientos en un sector especialmente propenso a las prácticas anticompetitivas ${ }^{12}$. A pesar de las posibles desviaciones de la regulación, los interesados no accionaban ningún procedimiento de revisión porque los recursos no eran eficaces ni precisamente rápidos. La duración de los procedimientos era extensa y apenas se adoptaban

\footnotetext{
10 V. AGUADO I CUDOLÀ (2017: 251 y ss.).

11 V. S. BACA ONETO (2006: 105 y ss.).

12 Esta constatación aparece en el Libro Verde sobre la modernización de la política de contratación pública de la Unión Europea. Hacia un mercado europeo de la contratación pública más eficiente, de 27 de enero de 2011, COM(2011) 15 final, págs. 34 y ss.
} 
medidas cautelares. Así que, dada la escasa probabilidad de obtener una resolución exitosa, se aplicaba la máxima de «no morder la mano que te da de comer». La ausencia de un sistema de tutela verdaderamente eficaz actuaba, de este modo, como un mecanismo disuasorio de la protección de los propios intereses ${ }^{13}$. Por esa razón, el legislador no alude en este precepto a la posible retroacción de actuaciones en la fase de preparación y adjudicación, que sería lo más deseable para garantizar el cumplimiento de las normas de procedimiento; o a la cancelación de la licitación, si el vicio afectaba al diseño de la licitación. El legislador no estaba pensando en un sistema de recursos rápido y eficaz. Por esa razón, la regulación legal de los efectos se queda corta en el actual contexto normativo.

Algo similar sucede con la regulación de los efectos de la invalidez de los actos que no sean preparatorios, es decir, los actos de ejecución. Según la Ley, la declaración de nulidad solo les afectará a ellos mismos y a sus consecuencias (art. 42.2 LCSP). Esta regulación podía tener sentido en un contexto en el que en la fase de ejecución solo estaban afectados los intereses del contratista y de la Administración. La nulidad de una modificación contractual solo afectaba a las partes del contrato. Sin embargo, en la actualidad, la fase de ejecución está vinculada a la adjudicación del contrato porque se entiende que en ese momento pueden ponerse de manifiesto vicios relacionados con la adjudicación. Por esa razón, las Directivas de 2014 regulan la subcontratación, la modificación del contrato y algunas causas de resolución. La situación actual del Derecho positivo en relación con los actos de ejecución es, por tanto, distinta. Así, por ejemplo, una modificación inválida del contrato puede dar lugar, no solo a la nulidad de la modificación, sino a la resolución del contrato, si no es posible continuar con su ejecución sin modificarlo (art. 203.2 in fine LCSP). Y la resolución del contrato conlleva también deberes indemnizatorios entre las partes, como señala el artículo 213 LCSP. Se observa, por tanto, una extensión de los efectos de la nulidad de la modificación al contrato. Esto es algo con lo que no contaba el redactor del precepto ahora recogido en el artículo 42 LCSP.

Del análisis expuesto, puede afirmarse que el legislador ha comenzado a prestar atención a los efectos derivados de la invalidez de los actos dictados en el marco del procedimiento de adjudicación de contratos públicos al introducir la regulación del denominado «recurso especial en materia de contratación» (arts. 44 y ss. LCSP) -derivado de la transposición de las denominadas «Directivas de recursos»- ${ }^{14}$. En ese momento, al regular el contenido de la resolución del recurso especial, establece los posibles efectos que pueden derivarse de un acto inválido en el seno del procedimiento de adjudicación del contrato: anulación de las decisiones ilegales, retroacción de actuaciones y, en su caso, indemnización por los daños y perjuicios ocasionados al recurrente (arts. 57 y 58 LCSP). El legislador ha eliminado la posibilidad de que la resolución del recurso especial reconozca directamente el derecho a la adjudicación de uno de los licitadores -que sí estaba previsto en el art. 47.2 in fine TRLCSP-, aunque en el caso de que exista un derecho de unos de los licitadores al contrato, el órgano contratante deberá hacer efectivo ese derecho.

A diferencia de los efectos derivados de la anulación de un contrato público, estos efectos sí se proyectan sobre la relación de la Administración con los posibles interesados en el contrato. Y son complementarios de los efectos que puedan derivarse del contrato inválido, que pueda haberse celebrado. Pero, además, hay que tener en cuenta que estos efectos acontecen en la realidad más allá de los supuestos susceptibles de recurso especial. Estos son los efectos habituales que se derivan de la declaración de invalidez en los procedimientos de adjudicación en la jurisprudencia contencioso-administrativa; aunque la duración de los procesos hará difícil la retroacción de actuaciones o la cancelación de la licitación en la práctica en muchas ocasiones. También cuando se regula la revisión de oficio, el legislador alude, en concreto, a la indemnización como posible efecto de la declaración de invalidez (art. 41 LCSP). Y lo mismo sucede cuando se regula la decisión de no adjudicar o celebrar el contrato y el desistimiento del procedimiento por la concurrencia de vicios insubsanables (art. 152 LCSP).

De todo lo expuesto hasta ahora, puede constatarse claramente que el catálogo de efectos derivados de la invalidez en materia contractual va más allá de la liquidación del contrato y la indemnización de los daños producidos y que la Ley no distingue entre los efectos derivados de los actos nulos y anulables. Esta última afirmación es importante, porque demuestra la inexistencia de una correlación entre invalidez e ineficacia. La doctrina administrativista ha denunciado que no es cierto que la producción de efectos de un acto administrativo se condicione a su ajuste al ordenamiento jurídico ${ }^{15}$. En muchos casos, actos inválidos producen

\footnotetext{
${ }_{13}$ Así se afirma en los Considerandos de la Directiva 89/665/CEE.

${ }^{14}$ M. ${ }^{a}$ I. GALLEGO CÓRCOLES (2011: 261). Las Directivas de recursos son las Directivas 89/665/CEE, 92/13/CEE y la Directiva 2007/66/CE, que reforma las anteriores.

${ }^{15}$ Al respecto, en extenso: T. CANO CAMPOS (2004: 194 y ss.); y (2017: 4).
} 
efectos sin que nadie -ni el particular, ni la Administración- se dirija contra esa situación, lo que permite su consolidación. Pero es que, además, el ordenamiento jurídico prevé con normalidad que se mantengan los efectos jurídicos de actos contrarios a derecho. Así sucede cuando la Administración ejercita sus potestades de revisión. En ese caso, el legislador considera que el deber de restablecer la legalidad tiene límites. De modo que no podrá revisarse un acto cuando por prescripción de acciones, por el transcurso del tiempo o por otras circunstancias, el resultado sería contrario a la equidad, la buena fe, el derecho de los particulares o a las leyes (art. 110 LPACAP). En el concreto ámbito de la contratación pública se admite el mantenimiento de los efectos de un contrato nulo cuando se pudiera producir un grave trastorno al servicio público (art. 42.3 LCSP) ${ }^{16}$. De modo que no es cierto que un acto inválido sea ineficaz, ni que desaparezcan los efectos que era susceptible de producir el acto anulado. Ni en el derecho positivo ni en la práctica existe una relación de causalidad entre invalidez e ineficacia ${ }^{17}$.

Desde un punto de vista metodológico, hay que tener en cuenta que la invalidez es un concepto jurídico elaborado por la dogmática clásica susceptible de aplicación dicotómica ${ }^{18}$. Un acto es inválido o no lo es. Dicho de otro modo, o es conforme con la norma del juicio de validez o no lo es. No cabe una tercera posibilidad ${ }^{19}$. La gravedad del vicio de nulidad determinará las vías que permiten impugnar el acto y el plazo para hacerlo. Pero la conclusión solo puede ser validez o invalidez. En el caso de la eficacia, sin embargo, cabe una aplicación matizada conforme a las circunstancias y los intereses en juego. De los efectos externos producidos por el acto en la realidad pueden subsistir unos y no otros ${ }^{20}$. La capacidad de configuración de los efectos va mucho más allá de decidir si se eliminan ex tunc o ex nunc. Al analizar los efectos derivados de la invalidez se realiza una ponderación de todos los intereses en juego con base en determinadas técnicas jurídicas como la de la protección de la confianza jurídica ${ }^{21}$. No hay una aplicación subsuntiva de la norma, sino una ponderación ${ }^{22}$. Por esa razón la conexión entre invalidez e ineficacia se apoya, a mi juicio, en una premisa metodológica defectuosa. De un concepto dogmático, estático, se pretenden inferir consecuencias dinámicas, ligadas a los efectos del acto.

\section{El momento en que tienen lugar los efectos de la invalidez}

En relación con el momento en que una declaración de nulidad despliega sus efectos, hay que atender a la regulación del artículo 42 LCSP. Conforme a este precepto: «[l]a declaración de nulidad de los actos preparatorios del contrato o de la adjudicación, cuando sea firme, llevará en todo caso consigo la del mismo contrato (...)». La literalidad de la norma parece establecer una condición para que se produzca la transmisión de los vicios de invalidez de los actos de preparación y adjudicación al contrato: la firmeza de esa declaración. Esta condición puede interpretarse como una excepción a la regla general de ejecutividad de los actos de las Administraciones Públicas sometidos a Derecho administrativo, que está prevista en la propia LPACAP (art. 98.1 c), cuando una disposición así lo establece. La LCSP establecería esa excepción al señalar que la ejecutividad de la declaración de nulidad de actos preparatorios o de adjudicación no se produce hasta que adquiere firmeza.

Esta interpretación puede tener en sentido en la medida en que la transmisibilidad de los vicios de la fase precontractual al contrato supone dotar a la Administración de la capacidad para anular el contrato sin que haya habido una revisión por parte de un juez y de que se haya garantizado la defensa del contratista. De hecho, no se reconoce en muchos ordenamientos jurídicos de nuestro entorno. De modo que, cuando se establece esta regulación tiene sentido que se quiera garantizar la firmeza de la declaración de nulidad antes de traspasar los efectos al contrato. En la medida en que no se señala cuál es el carácter de esa firmeza, podría entenderse que se trata de firmeza tanto en vía administrativa como judicial. Ese podría ser el sentido originario de la declaración del artículo 42 LCSP, que se dicta en un contexto en el que la tutela al licitador y la declaración de nulidad de los actos preparatorios y de adjudicación era algo totalmente excepcional. Apenas existían impugnaciones de ese tipo de actos.

\footnotetext{
${ }_{16}$ Sobre este último supuesto, J. A. MORENO MOLINA (2010: 161 y ss.).

17 J. A. SANTAMARÍA PASTOR (1975: 73 y ss.).

18 S. DÍEZ SASTRE, (2018a: 118 y ss.).

19 G. DOMÉNECH PASCUAL (2002: 212).

20 Sobre la distinción entre eficacia interna y externa, R. BOCANEGRA SIERRA (2011: 784 y ss.); también, T. CANO CAMPOS (2004: 171 y ss.).

21 M. REBOLLO PUIG (2009: 18); T. CANO CAMPOS (2004: 204).

22 J. M. ${ }^{a}$ RODRÍGUEZ DE SANTIAGO (2006: 26-27).
} 
El problema surge cuando la previsión tradicional de declaración de nulidad de actos precontractuales en la legislación de contratos debe compatibilizarse con la nueva regulación del recurso especial. De acuerdo con el artículo 59.1 LCSP, solo cabe recurso contencioso-administrativo contra la resolución de recurso especial. Y, conforme al artículo 59.2 LCSP, las resoluciones de los órganos de recursos contractuales serán directamente ejecutivas. En esa situación cabrían dos opciones: a) la primera es entender que esta norma relativa al recurso especial es una regla especial con respecto al artículo 42 LCSP y que tiene, por tanto, aplicación preferente, desplazando a la regulación general; pero que en el resto de casos, la firmeza se refiere a firmeza en sede judicial; o b) interpretar que, en realidad, esta regulación del recurso especial ayuda a interpretar el artículo 42 LCSP, de modo que la firmeza es firmeza únicamente en vía administrativa en todos los casos. Eso significaría que en vía de recurso ya se ha declarado la nulidad o que en vía de revisión de oficio se ha declarado la nulidad y que no caben más vías de revisión en sede administrativa.

Al respecto, hay que tener en cuenta que la jurisprudencia del Tribunal Supremo se ha pronunciado ya sobre casos en los que se produce una declaración de nulidad de una adjudicación de un órgano de recursos contractuales y no se ejecuta, manteniéndose la ejecución del contrato ${ }^{23}$. Al respecto, señala el Tribunal que hay que atender a la finalidad del recurso, la rapidez y eficacia, así como al efecto útil del Derecho europeo. Esos objetivos no se lograrían, si los efectos de la declaración de nulidad se dilataran hasta la resolución de un posible recurso contencioso-administrativo. Aunque el Tribunal Supremo no lo señala expresamente, interpreta que la firmeza del artículo 42 LCSP es firmeza en vía administrativa cuando se trata de asuntos recurribles mediante recurso especial.

Ahora bien, puesto que el sistema de revisión de decisiones en materia contractual es complejo, surge la duda de si la solución dada para los supuestos sometidos a recurso especial, es trasladable a todos los supuestos de impugnación de decisiones contractuales. De manera que hay que analizar si, cuando hay una declaración de nulidad de una adjudicación mediante recurso de reposición, por ejemplo, se produce directamente la nulidad del contrato con los efectos que ello conlleva. Al respecto, parece que la nueva cultura de tutela precontractual que se ha instaurado a partir del recurso especial puede extenderse a cualquier tipo de revisión en vía administrativa de decisiones contractuales; siempre que sea posible ir al contencioso-administrativo, requiriendo, en su caso, una suspensión de los efectos de la declaración de nulidad. Esta interpretación puede tener encaje en el sistema de tutela de los particulares, siempre que se garantice la posibilidad de que se adopten medidas cautelares, tal y como ha señalado el Tribunal Constitucional ${ }^{24}$. De ese modo, se garantizaría de forma equilibrada la ejecutividad de la resolución administrativa que declara la nulidad, así como la protección del contratista que ve en peligro el contrato que ha celebrado y que puede estar ejecutando.

Algo distinto sucede en los casos en que la Administración declara la lesividad de un acto anulable en el marco del procedimiento de contratación. En esos casos, el acto es ejecutivo y surte efectos hasta la firmeza de la sentencia judicial que decida sobre la anulación del acto. La declaración de lesividad es una actuación previa a la vía contencioso-administrativa a la que no se puede dotar de los mismos efectos que una declaración de nulidad en el marco de una revisión de oficio o de la resolución de un recurso administrativo ${ }^{25}$.

\section{LOS TIPOS DE EFECTOS DE LA INVALIDEZ}

\section{Los fundamentos de los efectos de la invalidez}

Como se acaba de ver, el Derecho positivo hace alusión a posibles indemnizaciones, anulaciones, retroacción de actuaciones y mantenimiento del contrato, entre otras consecuencias, cuando regula los efectos de la invalidez y de las vías de revisión de la actuación administrativa. Pero no establece un cuadro ordenado de los efectos de la invalidez y de los tipos de supuestos en que deben producirse unos u otros. Un modo de racionalizar los efectos de la invalidez consiste en encontrar las razones que subyacen a su regulación. Con esa finalidad, aquí se proponen tres fundamentos complementarios de los efectos de la invalidez en el ámbito contractual: la teoría del control de la discrecionalidad de la Administración; el derecho de los particulares a la tutela de sus posiciones jurídico-subjetivas; $y$ el deber de garantizar el buen funcionamiento del mercado y el interés público en la ejecución de los contratos. En seguida, se desarrolla cada uno de ellos

\footnotetext{
23 Por todas, las SSTS $3014 / 2013$ y $341 / 2015$

24 Por todas, la STC 148/1993.

25 STS 2868/2018.
} 
brevemente. Baste apuntar ahora que, con base en estos fundamentos es posible encontrar dos ejes que explican los distintos efectos de la invalidez: las reacciones vinculadas al restablecimiento de la legalidad, y a la ponderación de intereses que se produce en esos casos; y el resarcimiento de los daños y perjuicios que puedan haberse ocasionado como consecuencia de la actuación inválida de la Administración.

\subsection{La teoría del control de la discrecionalidad}

Los efectos derivados de la invalidez de los actos en materia contractual pueden ponerse en conexión, en primer lugar, con las exigencias de la teoría del control de la discrecionalidad administrativa ${ }^{26}$. La anulación del acto o del contrato es la consecuencia inmediata de un juicio de contraste entre la realidad y la norma jurídica aplicable que constata la invalidez de un acto. Sin embargo, las demás consecuencias ligadas a esa anulación (retroacción de actuaciones, condena a hacer a la Administración, mantenimiento de los efectos del contrato o cancelación de la licitación) se explican bien desde el punto de vista del control de la discrecionalidad de la Administración. La razón por la que se ordena una u otra consecuencia radica en la existencia o no de márgenes de discrecionalidad de la Administración, entendida como la necesidad de integrar el supuesto de hecho de una norma en sede aplicativa ${ }^{27}$.

Esto significa que solo cuando la decisión esté totalmente programada, esto es, cuando sea reglada, será posible anudar una consecuencia jurídica determinada al supuesto de hecho planteado ${ }^{28}$. Esto es lo que sucederá si, por ejemplo, los criterios de adjudicación eran conformes a derecho y aplicables automáticamente, pero se aplicaron mal ${ }^{29}$. En ese caso el control que puede realizarse sobre la actuación administrativa es positivo ${ }^{30}$. Existen suficientes criterios para decidir cuál era la única decisión conforme a derecho -y a la voluntad de la Administración fijada a través de los actos de preparación-. Por esa razón la Administración revisora y el juez pueden llegar a determinar cuál era la decisión que debía adoptarse y puede dictar una resolución de condena a la Administración ${ }^{31}$.

Junto a estos supuestos, es posible que en otros casos la discrecionalidad de la Administración no haya desaparecido por completo. Esto significa que, en el margen abierto por el legislador, la Administración ejerce parte de su discrecionalidad a través de los actos preparatorios del contrato, pero subsisten espacios de decisión discrecional. Esto es lo que sucede cuando se incorporan conceptos jurídicos indeterminados en los criterios de adjudicación, que han de ser objeto de un juicio de valor. En esos supuestos, la Administración debe buscar cuál es la mejor oferta en el margen de discrecionalidad abierto por ella misma. Por el contrario, el órgano revisor solo puede desechar las decisiones que no sean «aceptables»" ${ }^{32}$. Esta es la razón que explica por qué en ese tipo de supuestos el control ejercido sobre el acto administrativo solo puede ser negativo. No cabe sustituir la decisión tomada por otra, porque solo la Administración puede decidir cuál es la decisión adecuada. Es en este tipo de casos en los que la decisión de anulación de un acto en el marco del procedimiento de adjudicación de un contrato público debe ir acompañada de un deber de retrotraer las actuaciones al momento anterior a la comisión de la ilegalidad que ha dado lugar a la invalidez. De ese modo se restablece la legalidad y se respeta, al mismo tiempo, el margen de discrecionalidad que solo puede ejercer la Administración.

\subsection{La tutela de las posiciones jurídico-subjetivas de los particulares}

La otra cara de la moneda de la teoría de la discrecionalidad es la protección de las posiciones jurídicosubjetivas de los particulares. Desde este punto de vista se pone de manifiesto la insuficiencia de una construcción de los efectos de la invalidez apoyada en la mera ejecución de una declaración anulatoria. No basta con que teóricamente puedan derivarse efectos de la invalidez. Los efectos de la invalidez exigen eficacia en la tutela de los derechos e intereses de los ciudadanos y no meras declaraciones cuyo valor suele ser meramente nomofiláctico. En este plano entra en juego el derecho fundamental a la tutela judicial efectiva sin indefensión (art. $24 \mathrm{CE}$ ). Aunque la jurisprudencia constitucional se ha centrado en las garantías proce-

\footnotetext{
${ }^{26}$ Al respecto, S. GONZÁLEZ-VARAS IBÁÑEZ (2003: 131 y ss. y 136).

27 M. BACIGALUPO SAGGESE (1997: 204 y ss.).

${ }^{28}$ Se sigue en este punto la explicación y terminología de J. M. ${ }^{a}$ RODRÍGUEZ DE SANTIAGO (2016: 170 y ss.).

${ }^{29}$ S. DÍEZ SASTRE (2012: 113 y ss.).

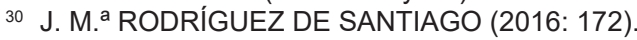

31 A. HUERGO LORA (2000: 214).

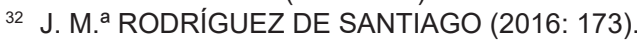


dimentales de este derecho, es preciso asegurar un contenido sustantivo de tutela que sea verdaderamente efectiva $^{33}$. En este sentido, de forma paralela a los efectos típicos de la invalidez, puede hablarse de tutela primaria o restitutoria y de tutela secundaria o resarcitoria.

El deber de restablecimiento de la legalidad interpretado en clave subjetiva se traduce en un deber de tutela restitutoria. Esto significa que, cuando se comprueba una falta de correlación entre el derecho y la realidad, es preciso corregir esa situación reponiendo al particular en su posición jurídico-subjetiva vulnerada. Para llevar a cabo esta operación es determinante analizar cuál es el contenido de la posición jurídica del particular. En el caso de los procedimientos de adjudicación de contratos públicos esta operación no es sencilla. Sin ánimo de exhaustividad, puede decirse que el particular tendrá derecho normalmente, bien a la tramitación del procedimiento conforme a derecho, bien a la adjudicación del contrato ${ }^{34}$. La forma de restituir estas posiciones deberá ser distinta.

La anulación del acto inválido, la retroacción de actuaciones y la cancelación del procedimiento serán formas de restablecer la legalidad en el primer supuesto. Si el particular solo tiene un derecho a que el procedimiento se ajuste a derecho, el ordenamiento jurídico no puede garantizarle nada más. De modo que habrá que anular el acto y retrotraer las actuaciones para que se repitan; o cancelar directamente el procedimiento para que vuelva a tramitarse de nuevo, si se considera oportuno. Por el contrario, si la posición jurídicosubjetiva del particular encierra un derecho al contrato, la forma idónea de tutela será obligar a la Administración a que le adjudique el contrato efectivamente. En ambos casos se dispensa al ciudadano una tutela restitutoria. Este tipo de tutela es el más eficaz de todos, puesto que es capaz de restablecer la legalidad vulnerada. De modo que es la forma de tutela más deseable, de ahí su posible caracterización como tutela primaria, siguiendo la terminología del derecho alemán (Primärrechtsschutz) ${ }^{35}$. En el plano constitucional, sin embargo, no existe una preferencia general a favor de este tipo de tutela en el derecho español ${ }^{36}$.

A pesar de que la tutela primaria es la más deseable, ya se ha expuesto anteriormente, que no siempre es realizable en la práctica. El juicio sobre los efectos de un acto declarado inválido puede conducir al mantenimiento de los efectos de un contrato nulo. Pero, además, en muchos casos -salvo en los supuestos de recurso especial-, los procedimientos de revisión de los actos de adjudicación se resuelven cuando el contrato ya se ha ejecutado. En cualquiera de los casos el restablecimiento de la legalidad no es posible. Quien debió ser adjudicatario nunca podrá serlo, porque se considera que existe un interés público que prima sobre su derecho. La única protección posible que queda entonces para la posición jurídico-subjetiva de ese particular es la indemnización por los daños y perjuicios sufridos ${ }^{37}$. Asimismo, hay que tener en cuenta que la restitución puede no ser suficiente para tutelar íntegramente al particular. De forma que, aun cabiendo la restitución, se hayan causado daños concomitantes que deban ser objeto de compensación. En todos estos casos debe garantizarse al particular una tutela resarcitoria o secundaria, en la medida en que puede ser supletoria a la tutela primaria en algunos casos.

Los daños susceptibles de tutela pueden referirse a la pérdida del contrato o a los gastos de preparación y participación en la licitación. Los más problemáticos en la práctica son los daños relativos a la pérdida del contrato. El artículo 42 LCSP establece, con respecto a los efectos de la invalidez de un contrato público, que las partes deberán restituirse las cosas y, cuando no sea posible, devolver su valor. Si se traslada este mandato a los casos de invalidez de un acto preparatorio del acto de adjudicación de un contrato público resultaría que la Administración que cometió una ilegalidad debe restituir la legalidad vulnerada. Cuando se pone de manifiesto que la legalidad vulnerada reconocía un derecho al contrato a un licitador determinado, la primera forma de restituir la legalidad es adjudicarle el contrato. Si eso no es posible, habría que devolverle su valor. Aquí es precisamente donde encaja la jurisprudencia contencioso-administrativa que reconoce que existe un deber de indemnizar por el beneficio industrial perdido cuando ya no es posible llegar a ejecutar el contrato. El deber de indemnizar puede añadirse al deber de restituir o bien sustituirlo cuando el restablecimiento de la legalidad ya no es posible ${ }^{38}$.

Ahora bien, la jurisprudencia contencioso-administrativa olvida la siguiente consecuencia que se deriva de la invalidez: la indemnización por los daños y perjuicios ocasionados. La devolución del valor del derecho

\footnotetext{
${ }^{33}$ S. DÍEZ SASTRE (2012: 92).

34 Ibidem, pág. 105 y ss

35 T. SCHNEIDER (2007: 46).

${ }_{36}$ Por todas, STC 32/82, de 7 de junio de 1982.

${ }^{37}$ M. $^{\text {a }}$. GALLEGO CÓRCOLES (2012: 168 y ss.).

38 S. GONZÁLEZ-VARAS IBÁÑEZ (2003: 145).
} 
al contrato no puede agotar las posibilidades indemnizatorias de un interesado en la licitación. Esa no puede ser la única consecuencia de la invalidez. En sede resarcitoria no es necesario probar que se tenía un derecho al contrato. La indemnización no está vinculada a la imposibilidad de ejecutar el contrato en estos casos. La indemnización se liga a la prueba de la existencia de un daño. Y esa prueba se somete a una serie de requisitos típicos de la responsabilidad de la Administración: que exista un daño efectivo, un nexo causal entre la actuación administrativa y el daño sufrido y que el daño sea imputable a la Administración ${ }^{39}$. De forma que, aunque no se pruebe que se tenía un derecho al contrato, es posible probar que sí se ha ocasionado un daño por la pérdida del contrato. Esta cuestión se desarrolla en detalle más adelante.

\subsection{Garantía de funcionamiento del mercado y del interés público en el contrato}

Junto a los fundamentos señalados para determinar los efectos de la invalidez, cabe añadir otro más, de carácter específico en el caso de la contratación pública. Se trata del deber de protección del buen funcionamiento del mercado, que está ligado a principios garantizados en la legislación de contratación pública, como la igualdad, no discriminación, concurrencia, publicidad y transparencia (art. 1 LCSP). La razón por la que la licitación debe cancelarse en algunos casos está ligada a la imposibilidad de subsanar el procedimiento desde el punto de vista del principio de competencia o de la garantía de confidencialidad. En esa misma línea, hay que interpretar que solo a través de la eficacia de las decisiones de invalidez se infunde confianza y seguridad en los operadores económicos para incentivar su participación en procedimientos de carácter competitivo. En este punto, el derecho europeo aporta una perspectiva que puede complementar una propuesta teórica sobre los efectos de la invalidez en los procedimientos de contratación pública, tal y como se expone a continuación.

Además, junto al buen funcionamiento del mercado, hay que tener en cuenta el interés público que subyace a los contratos públicos, que satisfacen las necesidades de la Administración. En la Ley el interés público aparece como valor a tener en cuenta a lo largo de la vida del contrato. Por eso cabe tramitar de forma urgente el expediente (art. 119.1 LCSP) si hay razones de interés público. Y solo por razones de interés público cabe no adjudicar o celebrar un contrato (art. 152.3 LCSP). Pero, el interés público es especialmente importante en la fase de ejecución. Por esa razón, se prevé la prórroga ex lege de los contratos en ciertas circunstancias, a las que se alude más adelante (art. 29.4 in fine LCSP); se permite mantener los efectos de un contrato inválido (art. 42.3 LCSP); y, también se reconoce una serie de prerrogativas a favor de la Administración ${ }^{40}$.

\section{El restablecimiento de la legalidad}

El efecto inmediato de la invalidez es el restablecimiento o restitución (restitutio in integrum) de la legalidad y de la posición jurídica vulnerada. Esto significa que debe reponerse la situación al momento previo a la comisión de la ilegalidad. La restitución constituye una institución fundamental en el ordenamiento jurídico, de carácter transversal ${ }^{41}$. El deber de reintegrar o restablecer la legalidad surge de un juicio actual entre la realidad y el derecho ${ }^{42}$. El paso previo al restablecimiento es la anulación del acto inválido. La nulidad constituye, de este modo, la «declaración institucional de la invalidez de un acto» ${ }^{43}$. El problema es que la forma en que debe restablecerse la legalidad vulnerada y declarada no está teorizada con el mismo grado de rigor. Los efectos anudados a la anulación pueden variar según los casos y los intereses en juego. Los efectos restitutorios típicos de la declaración de invalidez de un acto en un procedimiento de adjudicación serán la anulación del acto, la retroacción de actuaciones, la obligación de la Administración a hacer ${ }^{44}$, en ciertas circunstancias, la cancelación del procedimiento y, en su caso, la liquidación del contrato. Además, hay que tener en cuenta los supuestos en que puede considerarse necesario garantizar la continuidad del servicio,

39 L. MEDINA ALCOZ (2005: 204 y ss.).

40 La Administración puede modificar los contratos por razones de interés público (arts. 203, 261.1 b), 262, 290.1 LCSP); decidir el reequilibrio económico del contrato (art. 261.1 c) LCSP); rescatar un contrato unilateralmente para iniciar su gestión directa (arts. 279 c), 294 c) LCSP); o suprimir la explotación de las obras o de un servicio objeto de un contrato por razones de interés público (arts. 279 d), 294 d) LCSP). Además, la Ley limita la resolución del contrato por mutuo acuerdo al interés público (art. 212.4 LCSP); o cuando hay declaración de concurso, siempre que haya garantías suficientes en la ejecución (art. 212.5 LCSP).

${ }^{41}$ F. DE CASTRO Y BRAVO (1985: 508); I. RODRÍGUEZ FERNÁNDEZ (2009: 47).

42 I. RODRÍGUEZ FERNÁNDEZ (2009: 62).

${ }^{43}$ R. LETELIER WARTENBERG (2011: 95).

${ }^{44}$ Al respecto, V. S. BACA ONETO (2006: 347 y ss., 357,359 y ss. y 365 y ss.). 
lo que conducirá a una serie de efectos diversos, previstos en el ordenamiento jurídico. Hay otros efectos, como la responsabilidad disciplinaria o penal, que también podrían considerarse efectos de la invalidez de forma indirecta ${ }^{45}$, pero a los que no se hace referencia en este trabajo.

\subsection{La anulación}

En muchos casos de la invalidez de un acto se sigue exclusivamente de una declaración de nulidad. En la jurisprudencia contencioso-administrativa, en 2017 , cerca del $40 \%$ de los litigios planteados por licitadores resultó en una declaración anulatoria en primera y segunda instancia, mientras que ese porcentaje se eleva a más del $70 \%$ en casación ${ }^{46}$. El acto se declara nulo, sin que se vinculen otros efectos jurídicos a este pronunciamiento. Esta situación puede traer causa de las pretensiones del interesado, que se centraron exclusivamente en la declaración de nulidad con el fin de reclamar con posterioridad una indemnización en sede de responsabilidad patrimonial de la Administración. Pero también puede suceder que exista una indeterminación restitutoria. Esto es, que se deje para el momento de ejecución de la resolución anulatoria la fijación de las concretas medidas orientadas a restablecer la legalidad perdida. El problema en estos casos está en la demora de la tutela obtenida por el particular que debe esperar, en ocasiones, a un nuevo juicio en sede de ejecución de sentencia en torno a los efectos del acto inválido ${ }^{47}$.

Así, por ejemplo, en sede contencioso-administrativa se anula la resolución administrativa que preveía un contrato de suministro por la vía del procedimiento negociado sin publicidad al considerar que, siendo el contrato armonizado, ese supuesto de utilización de ese tipo procedimental no estaba previsto en la Directiva europea aplicable ${ }^{48}$.

En el caso de los órganos de recursos contractuales no existen datos detallados sobre los efectos reconocidos en la resolución, pero es presumible que la anulación sea muy común, en combinación con otro tipo de efectos, a los que se hace referencia en seguida.

\subsection{La retroacción de actuaciones}

Puesto que la anulación del acto inválido supone teóricamente la declaración de su ineficacia, es posible que la anulación del acto esté acompañada de un deber de retrotraer actuaciones ${ }^{49}$. Esto significa que, además de anular el acto, se obliga a la Administración a situarse en el momento anterior a la comisión de la ilegalidad para que vuelva a actuar eliminando los vicios en que incurrió. De ese modo se restablece el orden jurídico. Eso es a lo que se refiere la Ley cuando obliga a que las partes se devuelvan las cosas (art. 42 LCSP) -el problema es que, normalmente, no será posible, porque las prestaciones de los contratos, una vez que se han realizado, son difíciles de devolver-. Y eso mismo dispone el legislador en relación con los recursos administrativos (art. 119.2 LPACAP). Cuando se incurra en un defecto de forma y no se considere procedente resolver sobre el fondo del asunto, se debe ordenar la retroacción de actuaciones ${ }^{50}$. También puede suceder que en sede contencioso-administrativa la sentencia anule el acto impugnado y ordene la retroacción de actuaciones al momento inmediatamente anterior a la producción del vicio de legalidad identificado. Aunque en el caso de recursos interpuestos por licitadores, en 2017 solo el $10 \%$ de los casos se resolvió con una sentencia que ordenara la retroacción de actuaciones ${ }^{51}$.

La jurisprudencia reconoce en distintos supuestos el deber de la Administración de retrotraer actuaciones con el fin de tramitar el procedimiento sin los vicios identificados:

a) En un primer grupo de casos, la retroacción de actuaciones puede conducir a un resultado distinto del procedimiento. Así sucede cuando se adjudica el contrato con base en criterios no previstos en los pliegos, lo que determina su anulación y la retroacción de actuaciones al momento anterior a la adju-

\footnotetext{
${ }^{45}$ Con respecto a la obligación de dejar sin efecto los contratos derivados de actos de corrupción: C. AYMERICH CANO (2015).

${ }^{46}$ S. DÍEZ SASTRE (2018b: 139).

47 R. LETELIER WARTENBERG (2011: 110).

48 SAN (Sala de lo Cont.-Admvo., Secc. 5. ${ }^{\text {a) }}$, de 10 de diciembre de 2008, rec. cont.-admvo. núm. 318/2007. En un supuesto similar, la STS (Sala de lo Cont.-Admvo., Secc. 4. ${ }^{\text {a) }}$, de 30 de abril de 2008, rec. casación núm. 320/2007.

${ }^{49}$ Sobre esta cuestión, J. M. ${ }^{a}$ BAÑO LEÓN (2011: passim).

50 Al respecto, T. R. FERNÁNDEZ-RODRÍGUEZ (1969: 76).

51 S. DÍEZ SASTRE (2018b: 139).
} 
dicación ${ }^{52}$. En el mismo sentido, se anula el acto de exclusión de uno de los licitadores al considerar que debía haberse subsanado el defecto de bastanteo y se ordena la retroacción de actuaciones hasta el momento previo a la exclusión obligando a incluir a las entidades excluidas ${ }^{53}$. También se anula la adjudicación y se obliga a retrotraer las actuaciones al momento previo a la apertura de proposiciones económicas cuando se considera necesario dar la posibilidad de subsanar el error cometido por uno de los licitadores en la formulación de la proposición económica ${ }^{54}$. Lo mismo sucede cuando se anula un concurso por falta de publicidad y se impone la retroacción para publicitar el contrato adecuadamente ${ }^{55}$.

b) En un segundo grupo de supuestos, se obliga a retrotraer actuaciones para subsanar defectos formales que, en principio, no van a cambiar el resultado del procedimiento de adjudicación del contrato. Por ejemplo, cuando se anula la adjudicación de un contrato por falta de motivación de la propuesta de adjudicación y se ordena la retroacción para que se motive el acto prestando especial atención a la falta de capacidad técnica de la empresa recurrente ${ }^{56}$. O cuando falta el acto público de adjudicación de un contrato de gestión de servicios públicos y no se dio cuenta del contenido del informe técnico ${ }^{57}$.

En el ámbito europeo también se reconoce este efecto de la anulación de actos inválidos. Así, cuando se excluye ilegalmente a un licitador que propuso una oferta admisible, el Tribunal de Justicia entiende que los principios de igualdad de trato y no discriminación exigen que se anule la exclusión y que se repita el procedimiento de licitación. Esa obligación de repetición existe incluso cuando no pueda demostrarse que la participación de ese licitador habría cambiado el resultado de la adjudicación ${ }^{58}$.

\subsection{La condena a hacer a la Administración}

Junto a los casos expuestos, existen otro tipo de supuestos en los que se considera que la forma de restablecer la legalidad es imponer a la Administración la realización de una conducta concreta. En esos supuestos, puede que se reconozca el derecho de un tercero (normalmente el recurrente) a la adjudicación del contrato y que se obligue a la Administración a adjudicarle el contrato ${ }^{59}$.

Por ejemplo, cuando en un contrato de obras se excluyó a la recurrente por no haber probado que había realizado obras similares, se anula la adjudicación y se reconoce su derecho a la adjudicación del contrato al comprobar que su oferta era la más ventajosa. En este caso, como era previsible que en el momento de reconocer el derecho al contrato del recurrente el contrato ya estuviera ejecutado, la propia sentencia reconoce su derecho a indemnización por el lucro cesante ${ }^{60}$. O también cuando se demuestra que la Administración aplicó mal el baremo fijado en los pliegos, basado exclusivamente en criterios de aplicación automática, y resulta que la recurrente presentó la oferta económicamente más ventajosa ${ }^{61}$.

Pero lo más habitual en los casos de condena a hacer a la Administración será que, en sede de ejecución, se reconozca el derecho del contratista al pago de una cantidad reclamada previamente. En 2017, la jurisprudencia contencioso-administrativa reconoció un derecho al licitador recurrente en cerca del $60 \%$ de los casos en primera y segunda instancia ${ }^{62}$; en la mayoría de ellos se trataba de reclamaciones de cantidad.

\footnotetext{
52 STS (Sala de lo Cont.-Admvo., Secc. 5. a), de 30 de marzo de 1998, rec. apelación núm. 3939/1992.

53 STS (Sala de lo Cont.-Admvo., Secc. 4. ${ }^{\text {a) }}$, de 13 de julio de 2005, rec. casación núm. no disponible (RJI200519213); STS (Sala de lo Cont.-Admvo., Secc. 4. ${ }^{\text {}}$ ), de 11 de julio de 1991, rec. apelación núm. 1539/1988.

54 SAN (Sala de lo Cont.-Admvo., Secc. 4. ${ }^{a}$ ), de 6 de febrero de 2008, rec. cont.-admvo. núm. 314/2006. En el mismo sentido, la SAN (Sala de lo Cont.-Admvo., Secc. 8. ${ }^{\text {) }}$, de 13 de septiembre de 2000, núm. rec. no disponible, JURI2000।312052.

55 STS (Sala de lo Cont.-Admvo., Secc. 4. ${ }^{\text {a) }}$ ), de 23 de abril de 2008, rec. casación núm. 3862/2006; en igual sentido, STS (Sala de lo Cont.-Admvo., Secc. 5. ${ }^{a}$ ), de 30 de septiembre de 1998, rec. apelación núm. 1296/1992; STS (Sala de lo Cont.-Admvo., Secc. 4. a), de 20 de febrero de 1992, rec. apelación núm. 1522/1990.

56 STS (Sala de lo Cont.-Admvo., Secc. 4. ${ }^{a}$ ), de 14 de julio de 2009, rec. casación núm. 2610/2007. Una explicación detallada de estos supuestos, en S. GONZÁLEZ-VARAS IBÁÑNZZ (2003: 136 y ss.).

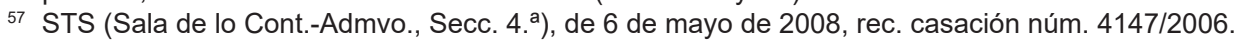

58 STJUE de 7 de abril de 2016, C-324/14, As. Partner Apelski Dariusz y Zarząd Oczyszczania Miasta.

59 A. HUERGO LORA (2000: 321).

60 STS (Sala de lo Cont.-Admvo., Secc. 5. a), de 9 de julio de 1997, rec. apelación núm. 13620/1991; también la STS (Sala de lo Cont.-Admvo., Secc. 5. ${ }^{a}$ ), de 9 de octubre de 1990, rec. apelación núm. no disponible, RJ।1990।7900.

61 STS (Sala de lo Cont.-Admvo., Secc. 4. ${ }^{\text {a) }}$, de 15 de noviembre de 2004, rec. casación núm. 6812/2001.

62 S. DÍEZ SASTRE (2017: 139).
} 


\subsection{La cancelación de la licitación}

En algunos supuestos la anulación de la actuación inválida va acompañada de una condena a la Administración a cancelar el procedimiento de licitación. Se trata de un tipo específico de condena a hacer a la Administración. Se trata de supuestos en los que la anulación de una pieza determinada del procedimiento impide que pueda volver a reanudarse con normalidad. No se pueden retrotraer actuaciones al momento previo a la comisión de la ilegalidad porque se afectó a un elemento esencial en la configuración de la licitación ${ }^{63}$.

Así, hay supuestos en que la retroacción de actuaciones supone volver a realizar la licitación. Por ejemplo, cuando se anula una licitación por no haber separado adecuadamente la licitación de la redacción del proyecto de obra y su ejecución. Se obliga a repetir la licitación de forma separada ${ }^{64}$. Lo mismo sucede cuando se anula un criterio de adjudicación por ser contrario a derecho. La jurisprudencia europea considera necesario cancelar la licitación y repetirla de nuevo. De lo contrario se produciría un cambio de criterios sobre la marcha que no está permitido en las reglas de contratación ${ }^{65}$. En el caso concreto de los criterios de adjudicación es necesario que se mantenga una misma interpretación durante todo el procedimiento ${ }^{66}$.

Más allá de los casos en que la anulación del acto se liga a la cancelación, hay que referirse a la posibilidad de que la invalidez lleve a la propia Administración a cancelar la licitación. El legislador prevé en la nueva LCSP que, cuando se hayan producido infracciones no subsanables en la preparación del contrato o de las normas reguladoras del procedimiento, la Administración puede desistir sin que ello impida que pueda volver a abrir una nueva licitación con el mismo objeto con posterioridad (art. 152.2 y 4 TRLCSP). Este desistimiento debe tener lugar necesariamente antes de la formalización del contrato, de acuerdo con el artículo 152.2 LCSP -anteriormente, el art. 155.2 TRLCSP establecía la adjudicación como límite para el desistimiento-. Puede entenderse, por tanto, que en el caso de que se haya producido un vicio de invalidez, la Administración puede cancelar directamente el procedimiento sin necesidad de esperar a una impugnación de un tercero o a su terminación para abrir un procedimiento de revisión de oficio. Este supuesto hay que diferenciarlo de la decisión de no adjudicar o celebrar el contrato, que se refiere a una ponderación del interés público que conduce a la cancelación de la licitación (art. 152.2 y 3 LCSP). No se trata, por tanto, necesariamente, de un supuesto de invalidez.

\subsection{La liquidación del contrato}

Las consecuencias que se han señalado hasta el momento afectan fundamentalmente a los casos en que la invalidez afecta a un acto de preparación o adjudicación. En estos supuestos, la invalidez de estos actos se contagia al contrato que se hubiera celebrado con posterioridad. En esas circunstancias, así como en el caso de que el contrato devenga inválido por otras razones, la forma de restablecer la legalidad vulnerada será la liquidación del contrato, así como la restitución de las cosas que las partes hubieran intercambiado. En caso de que no sea posible la restitución, se devolverán su valor (art. 42.1 LCSP). Esto será habitual, puesto que muy posiblemente el contrato o gran parte del contrato se habrá ejecutado y será difícil que las partes se restituyan las cosas. Por esa razón, esta obligación de devolver el valor de las cosas intercambiados contiene un deber de que la Administración abone, en su caso, la contraprestación debida por los trabajos realizados, que será la parte del precio que corresponda. Aunque en la práctica en estos casos se invoca la teoría del enriquecimiento sin causa ${ }^{67}$, no parece necesario acudir a esta construcción, en la medida en que la propia LCSP obliga a que las partes se devuelvan las cosas o, en su caso, su valor ${ }^{68}$.

${ }^{63}$ En el ámbito del derecho administrativo sancionador se defiende también la imposibilidad de retrotraer el procedimiento cuando se han vulnerado derechos fundamentales. Al respecto, en detalle, T. CANO CAMPOS (2012: 851 y ss.).

${ }^{64}$ STS (Sala de lo Cont.-Admvo., Secc. 7. ${ }^{2}$ ), de 17 de octubre de 2011, rec. casación núm. 2172/2009.

${ }^{65}$ STJUE de 4 de diciembre de 2003, C-448/01, As. EVN AG, Wienstrom GmbH c. Republik Österreich.

66 STJUE de 18 de octubre de 2001, C-19/00, As. SIAC Construction Ltd y County Council of the County of Mayo.

${ }_{67}$ Sirva de ejemplo el Dictamen del Consejo de Estado, referencia 2490/2007, de 24 de enero de 2008, referido a un caso en el que se adjudica como contrato menor un contrato que debería haberse licitado conforme a la legislación vigente.

${ }^{68}$ En este sentido, V. S. BACA ONETO (2006: 359 y ss.); y V. AGUADO I CUDOLÀ (2017: 245 y 246). 


\subsection{La garantía de la continuidad del servicio}

Otro de los posibles efectos que pueden derivarse de la invalidez de un acto o del contrato es la necesidad de garantizar la continuidad del servicio. Esto es lo que sucede cuando se pondera el deber de restablecer la legalidad y la necesidad de obtener las prestaciones derivadas del contrato, por ejemplo, para la garantía de un servicio público. En esos casos, la propia normativa, europea y nacional, prevén la posibilidad de mantener los efectos del contrato, ponderando el interés general por encima de la restitución de la legalidad vulnerada. Aunque los efectos en uno y otro caso, son distintos, como se ve más adelante.

Pero también pueden plantearse problemas de garantía de continuidad del servicio en otros casos ${ }^{69}$. Por ejemplo, cuando una licitación pública se paraliza o se retrasa debido a la existencia o posible existencia de vicios de invalidez, puede producirse un vacío en la cobertura de la necesidad pública que iba a satisfacerse con el contrato. Esta situación se agrava cuando el objeto del contrato es la prestación de un servicio público. En esos supuestos no es fácil encontrar una vía para satisfacer la necesidad de prestación del servicio durante ese periodo. Sin embargo, la legislación obliga a prestar el servicio adecuadamente. Aparece, así, una tensión entre el deber de la Administración de prestar un servicio determinado y la inexistencia de cauces legales expresamente previstos para hacer frente a esa situación. Es en este contexto donde se plantean los habituales problemas ligados a la prórroga del contrato, la tácita reconducción del mismo o el reconocimiento extrajudicial de créditos $^{70}$. Seguidamente se alude a estos supuestos.

\subsubsection{El mantenimiento de los efectos del contrato inválido}

Junto a los efectos típicos derivados de la invalidez de los actos de preparación y adjudicación y de los contratos públicos, hay otras consecuencias previstas con el fin de satisfacer las exigencias derivadas de la ponderación entre el interés general en la ejecución del contrato y la protección de la legalidad. Uno de los problemas más importantes ligado a los efectos de la invalidez en los procedimientos de contratación pública es la imposibilidad de ejecutar las resoluciones anulatorias, restableciendo la legalidad vulnerada. En muchos supuestos esta situación tiene su origen en la imposibilidad material de restituir las cosas al momento previo de la infracción porque el contrato ya está ejecutado. En otros, la razón está en la necesidad de mantener la ejecución del contrato por razones de interés general. En este segundo tipo de casos no se duda de la invalidez del contrato, pero un juicio de ponderación hace primar otros intereses sobre el deber de restaurar la legalidad vulnerada. Así lo ha previsto tradicionalmente el Derecho español (art. 43 Reglamento de Contratación de las Corporaciones Locales) y, en la actualidad, el Derecho europeo (art. 2 quinquies Directiva 2007/66/CE) ${ }^{71}$.

Como se ha apuntado más arriba, conforme al artículo 42.3 LCSP, si la declaración de nulidad produjese un grave trastorno al servicio público, se puede disponer la continuación de los efectos del contrato, hasta que se adopten medidas urgentes para evitar el perjuicio. De manera que no solo es posible que se mantengan los efectos que ha producido un contrato hasta que se declara inválido, sino que cabe mantener sus efectos hacia el futuro ${ }^{72}$. Esta previsión sería aplicable a todos los contratos celebrados por el sector público. Sin embargo, esta previsión no refleja suficientemente las exigencias del Derecho europeo.

La Directiva 2007/66/CE prevé una serie de casos en los que debe producirse la ineficacia del contrato por la vulneración del plazo de espera entre adjudicación y formalización del contrato; del plazo suspensivo para interponer el recurso contractual; o de las normas de publicidad del contrato, fundamentalmente. En esos supuestos, el contrato debe devenir ineficaz, salvo que concurran razones imperiosas de interés general, que justifiquen el mantenimiento de los efectos del contrato. En concreto, establece que en esos casos se considerará que los intereses económicos constituyen razones imperiosas en este sentido, en los casos excepcionales en que la ineficacia del contrato tuviera consecuencias desproporcionadas; sin que los intereses económicos ligados directamente al contrato puedan constituir razones imperiosas de interés general -es el caso de los costes derivados del retraso en la ejecución, los derivados de la convocatoria de un nuevo procedimiento, los derivados del cambio de operador económico y los vinculados a las obligaciones jurídicas derivadas de la ineficacia- (art. 2 quinquies 3 ).

69 Al respecto, V. AGUADO I CUDOLÀ (2017: 236 y ss.).

70 Sobre esta cuestión, con respecto a la regulación tradicional en el contrato de gestión de servicios públicos, J. F. RODRÍGUEZARANA (1988: 137 y ss.).

71 V. AGUADO I CUDOLÀ (2017: 247)

72 S. BACA ONETO (2006: 365 y ss.). 
El anterior artículo 38 TRLCSP recogía los efectos de la nulidad en esos casos. Pero ese precepto ya no tiene correspondencia en la LCSP. De modo que hay que hacer un esfuerzo por interpretar el Derecho nacional conforme a las previsiones de la Directiva. Si se incurre en una de las causas de nulidad reguladas actualmente en el artículo 39.2 c), d), e) o f) LCSP, será posible mantener los efectos del contrato cuando concurra un grave trastorno al servicio público, interpretado como razón imperiosa de interés general. En ese caso, dispone la Directiva que los Estados dispongan que se apliquen sanciones alternativas (art. 2 sexies 2 Directiva 2007/66/CE). En ese sentido, prevé dos tipos de consecuencias: la imposición de multas económicas o la reducción de la duración del contrato. El desarrollo de las mismas se deja a los Estados miembros. En cualquier caso, las medidas deben ser efectivas, proporcionadas y disuasorias, para que desincentiven las conductas contrarias a Derecho. Asimismo, la norma precisa que la obligación de indemnizar los daños y perjuicios no se considera una sanción adecuada.

El legislador español transponía esta regulación en el artículo 38.3 TRLCSP y, además, preveía la posible imposición de sanciones de carácter disciplinario (art. 38.4 TRLCSP). Pero esta regulación se suprime en la nueva LCSP. Ciertamente, la Comisión ha considerado recientemente que la mayoría de los Estados emplean estas sanciones de forma esporádica, porque se considera una herramienta poco eficaz, que consiste en una mera reubicación de fondos ${ }^{73}$. Sin embargo, parece que la supresión de las sanciones alternativas implica que, en los casos en que se mantienen los efectos del contrato, no se deriva ninguna consecuencia en la práctica de la declaración de invalidez del contrato. Se pierde, así, la posibilidad de que el órgano responsable de un posible vicio de invalidez experimente algún perjuicio como consecuencia de su conducta.

\subsubsection{La prórroga «ex lege» del contrato}

Se ha señalado que otros supuestos en los que pueden derivarse problemas con la continuidad del servicio, son aquellos en los que no es posible encadenar a tiempo los contratos. De modo que la Administración no tiene manera de recibir las prestaciones que requiere. Para resolver muchos de estos supuestos, el nuevo artículo 29.4 in fine LCSP prevé una prórroga legal del contrato cuando al vencimiento de un contrato no se hubiera formalizado el nuevo contrato para garantizar la continuidad de la prestación. Para que esta prórroga se aplique, es necesario que el desajuste entre la extinción del contrato y la formalización del nuevo contrato se deba a «incidencias resultantes de acontecimientos imprevisibles para el órgano de contratación» producidas en el procedimiento de adjudicación. Además, deben existir razones de interés público para no interrumpir la prestación. El límite de la prórroga es de un periodo máximo de nueve meses, sin que se modifiquen las condiciones del contrato, siempre que el anuncio de licitación del nuevo contrato se hubiese publicado, al menos, tres meses antes de la finalización del contrato originario. De este modo, el legislador pretende canalizar algunos de los supuestos en que, por ejemplo, se interponen sucesivos recursos especiales de contratación con efectos suspensivos, que impiden tramitar a tiempo el procedimiento de adjudicación de un nuevo contrato.

\subsubsection{La doctrina del enriquecimiento injusto}

En los casos en que la Administración no puede prorrogar legalmente los efectos del contrato a extinguir, no es infrecuente la situación en la que un particular lleva a cabo una prestación a favor de la Administración, sin que esta pueda atender la factura girada por el tercero, por no haberse seguido los procedimientos establecidos tanto en la normativa presupuestaria, como en la relativa a la contratación pública. En estos supuestos, el proveedor se encuentra con que, a pesar de haber realizado efectivamente la prestación encargada, no obtiene a cambio la contraprestación acordada. En esos casos, el tercero de buena fe que contrata con la Administración y cumple con las obligaciones a su cargo no puede verse perjudicado patrimonialmente, en el sentido de que su empobrecimiento produzca el correlativo aumento patrimonial de la Administración contratante ${ }^{74}$.

\footnotetext{
73 Informe de la Comisión al Parlamento Europeo y al Consejo sobre la eficacia de la Directiva 89/665/CEE y la Directiva 92/13/ CEE, modificadas por la Directiva 2007/66/CE, en cuanto a los procedimientos de recurso en el ámbito de la contratación pública, de 24 de enero de 2017, COM(2017) 28 final, pág. 5. G. GARCíA ÁLVAREZ (2018: 833); S. DÍEZ SASTRE, (2018c: 593).

74 J. I. VALERO ESCRIBANO (2015: 163 y ss.).
} 
A pesar de que este tipo de situaciones son relativamente habituales, no existe un precepto legal en nuestro país -a diferencia de lo que ocurre en otros ordenamientos jurídicos ${ }^{75}$ - que permita resolver todos estos supuestos. Únicamente se ha previsto una posibilidad de prórroga legal, que acaba de exponerse. Más allá de los supuestos cubiertos por esa prórroga, la jurisprudencia civil ha ido configurando la doctrina del enriquecimiento injusto (como principio general y como acción) que, aun con matices ${ }^{76}$, se aplica también en el orden contencioso-administrativo desde hace décadas ${ }^{77}$. Conforme a esa doctrina deben concurrir una serie de requisitos: a) el enriquecimiento o aumento del patrimonio del enriquecido, constituido por cualquier ventaja o atribución patrimonial abocada a producir efectos definitivos; b) el empobrecimiento de quien reclama ha de ser pecuniariamente apreciable y no debe provenir directamente del comportamiento de quien lo sufre; c) existencia de relación causal entre el empobrecimiento y el enriquecimiento, dicho en otros términos, que al enriquecimiento siga un correlativo empobrecimiento; y d) la falta de causa o de justificación del enriquecimiento y del correlativo empobrecimiento ${ }^{78}$.

EI TS admite que basta con haber creado la apariencia de que la Administración se haría cargo de los costes para entender que se produce un enriquecimiento injusto al que debe hacerse frente ${ }^{79}$. Así sucede, por ejemplo, cuando se anuncia una modificación del contrato que no llega a formalizarse y el contratista ejecuta el contrato dando por hecho que sí está formalizada. En ese caso la Administración debe abonar los gastos derivados de esa ejecución, pues de lo contrario se produciría un enriquecimiento injusto. A estos efectos, no es relevante que el contratista pudiera conocer que incurría en un exceso de gasto, como ha afirmado el TS en sentencia dictada en unificación de doctrina ${ }^{80}$.

Conforme a la jurisprudencia, no es relevante que el empresario pudiera conocer hipotéticamente las dificultades técnicas para hacer frente a las prestaciones exigidas por la Administración. Lo trascendente es que la Administración ha solicitado y aceptado los servicios prestados por el concesionario más allá de lo posible conforme al gasto anual máximo estipulado en el contrato y ello supone un enriquecimiento injusto que debe repararse. Con respecto a la cuantía que efectivamente debe satisfacerse con ocasión del enriquecimiento injusto, la jurisprudencia del TS ha señalado que únicamente cabe indemnizar por los conceptos que, efectivamente, han enriquecido a la Administración. Esto significa que no es posible indemnizar por los intereses, el IVA devengado, el beneficio industrial o los gastos generales. Únicamente deberá abonarse la cuantía correspondiente a la efectiva prestación del servicio ${ }^{81}$.

Este enriquecimiento sin causa puede resolverse tanto en el ámbito administrativo como en el judicial. En efecto, la creación jurisprudencial del concepto de enriquecimiento injusto ha cristalizado en la definición de un principio, así como en el reconocimiento de una acción específica (actio in rem verso), que se sustanciaría en el orden contencioso-administrativo y que prescribiría a los cuatro años, en aplicación analógica de lo dispuesto en el art. 25 LGP $^{82}$. Esta acción estaría a disposición del contratista que ha experimentado los daños que han dado lugar al enriquecimiento injusto de la Administración. La otra vía posible para reparar el enriquecimiento injusto de la Administración sería el reconocimiento extrajudicial de créditos. Sin embargo, esta posibilidad se ha de entender como una ultima ratio, que debe ir acompañada en todo caso de la regularización de la contratación del bien o servicio requerido por la Administración ${ }^{83}$.

75 Es habitual citar como ejemplo de contraste de la normativa española el artículo 812 del Bürgerliches Gesetzbuch (Código Civil alemán), en el que se consagra expresamente la obligación de restituir para quien por prestación de otro, o de otro modo a costa de este, se enriquece sin causa.

76 STS (Sala de lo Contencioso-Administrativo, Secc. 4. ${ }^{\text {) }}$, de 15 de abril de 2002, rec. casación núm. 9281/1996, FD 4. ${ }^{\circ}$

77 Al respecto, por todos, M. REBOLLO PUIG (1994: 10-12 y ss.); V. AGUADO I CUDOLÀ (2017: 260 y ss.).

78 STS (Sala de lo Contencioso-Administrativo, Secc. 4. ${ }^{a}$ ), de 15 de abril de 2002, rec. casación núm. 10381/1997, FD 6. ${ }^{\circ}$; reiterada en innumerables ocasiones como, por ejemplo, en la STS (Sala de lo Contencioso-Administrativo, Secc. $4 .^{a}$ ), de 11 de mayo de

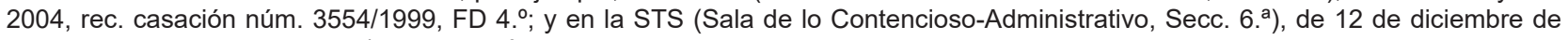
2012, rec. casación núm. 5694/2010, FD 5.․

79 STS (Sala de lo Contencioso-Administrativo, Secc. 5. ${ }^{a}$ ), de 21 de septiembre de 2000, rec. casación núm. 7562/1994, FD 6..

80 STS (Sala de lo Contencioso-Administrativo, Secc. 7. a), de 28 de enero de 2016, rec. casación para la unificación de doctrina núm. 2603/2015, FD $4 .^{\circ}$

81 STS (Sala de lo Contencioso-Administrativo, Secc. 4. ${ }^{\text {a) }}$, de 21 de junio de 2009, rec. casación núm. 5969/2007, FD 5. ${ }^{\circ}$.

82 Tal y como se señaló, si bien con referencia al plazo de cinco años que se establecía en el art. 46 de la anterior Ley General Presupuestaria, en la STS (Sala de lo Contencioso-Administrativo, Secc. 7. a), de 27 de enero de 2003, rec. casación núm. 2876/2000.

83 Al respecto, T. MOREO MARROIG (2015: passim); y V. AGUADO I CUDOLÀ (2017: 266 y ss.). 


\section{El resarcimiento de daños y perjuicios}

El último de los efectos típicos ligados a la declaración de invalidez es el resarcimiento de los daños y perjuicios ocasionados. Este deber indemnizatorio no es un efecto que aparezca de forma aislada con respecto al resto de efectos expuestos. De hecho, es una consecuencia complementaria a las que acaban de exponerse ${ }^{84}$. Junto a un fallo anulatorio, de retroacción de actuaciones, de condena a hacer o de cancelación del procedimiento, es posible encontrar un deber de indemnización por los daños y perjuicios ocasionados. En este punto, hay que diferenciar entre la tutela que requerirá el contratista que pierde el contrato -adjudicado inválidamente- y la que solicitará un licitador preterido.

\subsection{Los daños causados al licitador}

En el primer caso, normalmente el daño alegado por el particular será el beneficio perdido por no haber obtenido el contrato. Pero también es posible que se solicite una compensación de los daños sufridos como consecuencia de la cancelación de la licitación que hizo inútiles los gastos realizados en la preparación y participación en el procedimiento ${ }^{85}$. La anulación de un acto -como puede ser el acto de adjudicación de un contrato- es compatible con la obligación de la Administración de indemnizar a quien debió ser adjudicatario ${ }^{86}$. Así, por ejemplo, cuando se anula la adjudicación y se comprueba que el recurrente tenía derecho al contrato, al haber presentado la oferta económicamente más ventajosa, al fallo de anulación del contrato y de reconocimiento del derecho del recurrente a ser adjudicatario, puede establecerse un derecho a la indemnización por el beneficio dejado de obtener, puesto que la ejecución del contrato, normalmente, ya no es posible ${ }^{87}$. Es más, puede suceder que, como consecuencia de la invalidez de un acto en un procedimiento de adjudicación se determine la anulación del acto viciado, se ordene la retroacción de actuaciones para tramitar el procedimiento conforme a Derecho y que se determine que, en caso de que el recurrente resulte adjudicatario se le indemnice por el beneficio industrial perdido (el $6 \%$ del precio de adjudicación del contrato). En estos casos se parte de la imposibilidad de que el recurrente llegue a ejecutar efectivamente el contrato cuando se vuelva a tramitar el procedimiento debido al tiempo que previsiblemente habrá transcurrido ${ }^{88}$.

El problema está en que, en muchas ocasiones la jurisprudencia exige que se pruebe el derecho del recurrente a la adjudicación del contrato para reconocer una indemnización por daños y perjuicios ${ }^{89}$. Y esta prueba entraña muchas dificultades. Esto significa que en aquellos casos en los que ya no sea posible restablecer la legalidad por alguna de las vías señaladas -retroacción de actuaciones, condena a hacer o cancelación del contrato- porque, por ejemplo, el contrato ya esté ejecutado, la invalidez puede no llegar a producir efecto alguno si no se logra probar que se habría sido el adjudicatario ${ }^{90}$. De hecho, en la práctica de la jurisprudencia contencioso-administrativa apenas se reconoce un derecho a indemnización a favor de los licitadores ${ }^{91}$. Lo que probablemente pueda estar ligado a esta exigencia excesiva de prueba del daño.

Con respecto a los conceptos indemnizables en concepto de pérdida del contrato existe una opinión unánime favorable a indemnizar el beneficio industrial perdido a quien debería haber sido adjudicatario. Ese beneficio industrial se cifra en el 6\% del precio de adjudicación del contrato (art. 264.4 LCSP - anteriormente el porcentaje se refería al presupuesto de ejecución material). Se entiende, así, que se indemniza por los beneficios dejados de obtener. Este porcentaje tiene su origen en la previsión del art. 68 del Decreto 3410/1957, de 25 de noviembre, por el que se aprueba el Reglamento General de Contratos del Estado; asimismo, se preveía en el art. 193.3 del Real Decreto Legislativo 2/2000, de 16 de junio, por el que se aprueba el Texto Refundido de la Ley de Contratos de las Administraciones Públicas. Ahora bien, hay otros conceptos

84 T. CANO CAMPOS (2017: 319 y ss.); S. GONZÁLEZ-VARAS IBÁÑEZ (2003: 145).

85 S. DÍEZ SASTRE (2012: 279 y ss.).

86 STS (Sala de lo Cont.-Admvo., Secc. 7.a), de 7 de mayo de 2012, rec. casación núm. 3819/2008.

87 STS (Sala de lo Cont.-Admvo., Secc. 4. ${ }^{\text {a) }}$, de 27 de octubre de 2004, rec. casación núm. 2029/2000; y STS (Sala de lo Cont.Admvo., Secc. 7. $\left.{ }^{a}\right)$, de 25 de enero de 2000, rec. casación núm. 6382/1993.

${ }_{88}$ En este sentido, la SAN (Sala de lo Cont.-Admvo., Secc. 8. ${ }^{a}$ ), de 3 de marzo de 2010, rec. cont.-admvo. núm. 32/2007. Un pronunciamiento equivalente con respecto a un contrato de obras en la STS (Sala de lo Cont.-Admvo., Secc. 4. ${ }^{\text {a) }}$, de 2 de julio de 2004 , rec. casación núm. no disponible, RJI200416730; también, con respecto a un contrato de obras la STS (Sala de lo Cont.-Admvo., Secc. 5. $\left.{ }^{\circledR}\right)$, de 9 de julio de 1997, rec. apelación núm. 13620/1991.

${ }_{89}$ En esta línea, la STS (Sala de lo Cont.-Admvo., Secc. 4. ${ }^{\text {a) }}$, de 12 de mayo de 2009, rec. casación núm. 5101/2007. Al respecto, M. ${ }^{a}$ I. GALLEGO CÓRCOLES (2012: 167 y ss.).

90 STS (Sala de lo Cont.-Admvo., Secc. 4. ${ }^{\text {a) }}$, de 12 de mayo de 2009, rec. casación núm. 5101/2007.

91 S. DÍEZ SASTRE (2018b: 139). 
que pueden ser indemnizables si logran probarse adecuadamente: por ejemplo, los daños sufridos, en su caso, por la inactividad de equipos necesarios para la ejecución del contrato y el pago del salario de quien habría ejecutado el contrato. Otro concepto cuya indemnización es más dudosa es la pérdida de negocio que se deriva de no haber accedido al contrato ${ }^{92}$.

\subsection{En especial, la flexibilización de los requisitos ligados al deber resarcitorio}

Las reglas expuestas en torno a la indemnización al licitador, deben interpretarse conforme a las exigencias del Derecho europeo. Conforme a este Derecho se deriva un deber resarcitorio de la Administración por violación de las normas en materia de contratación pública cuando concurren los requisitos generales de responsabilidad por incumplimiento: la norma violada ha de conferir derechos, debe existir un nexo causal entre el daño producido y la ilegalidad cometida y la violación debe ser suficientemente caracterizada. Todo ello en el marco de aplicación de los principios de equivalencia y efectividad ${ }^{93}$. Ahora bien, estos requisitos generales se modulan en el ámbito de la contratación pública, tanto en lo referido a la prueba del nexo de causalidad, como en lo que afecta al título de imputación del daño a la Administración:

a) El artículo 2.7 Directiva 92/13/CEE establece que «[c]uando una persona interponga una demanda por daños y perjuicios por los gastos habidos en la preparación de una oferta o la participación en un procedimiento de formalización, únicamente se le exigirá que pruebe que ha habido violación del Derecho comunitario en materia de formalización de contratos o de las normas nacionales que transponen ese Derecho, y que hubiera tenido una posibilidad real de obtener el contrato, posibilidad que se ha visto comprometida debido a esta violación». Esto significa que la prueba del nexo de causalidad entre el daño producido y la actuación administrativa se relaja. No es necesario demostrar que se habría obtenido el contrato, sino que se tenía una "posibilidad real» de obtenerlo. Esto no puede traducirse en un derecho a la indemnización por haber participado en la licitación. Pero sí hace posible que varios licitadores puedan recibir una indemnización en el mismo procedimiento, si todos demuestran que tenían una posibilidad real de obtener el contrato. En ese caso, la indemnización por el beneficio industrial deberá modularse en atención a las probabilidades existentes de haber obtenido el contrato ${ }^{94}$. En ese juicio sería determinante el número de participantes en la licitación, así como el tipo de contrato y los criterios de adjudicación ${ }^{95}$. Sin perjuicio de las complejidades técnicas que plantea la aplicación de esta regulación ${ }^{96}$, lo cierto es que esta regulación consigue ampliar el número de supuestos en los que es posible reconocer el derecho a una indemnización por los daños derivados de un acto inválido.

b) Otro de los criterios fundamentales de flexibilización de los requisitos que determinan el surgimiento de un deber resarcitorio es la prohibición de la culpa como título de imputación para imponer la indemnización de los daños y perjuicios irrogados. El Tribunal de Justicia ha establecido de forma reiterada que, aunque las condiciones de indemnización se determinan con base en el principio de autonomía procesal de los Estados y en los principios de equivalencia y efectividad, no cabe supeditar la indemnización a la exigencia de culpa de la Administración. Esto es así, incluso cuando el Derecho nacional establezca una presunción de culpa supeditable a la prueba en sentido contrario del poder adjudicador. Se entiende que la exigencia de culpa es contraria a la rapidez y eficacia de los recursos ${ }^{97}$. Asimismo, se interpreta que esa regulación entraña un riesgo de que el lesionado por una decisión contraria a Derecho no sea indemnizado o de que obtenga la indemnización tardíamente, debido a la dificultad para probar la culpa o dolo de la Administración ${ }^{98}$. El Derecho europeo se fija, así, en los efectos previsibles de una regulación que exija la culpa y modula las normas de responsabilidad para que en la práctica sea verdaderamente posible obtener una indemnización.

Junto a estas previsiones, hay que referirse a otro criterio que flexibiliza el surgimiento de un deber resarcitorio. El Tribunal de Justicia prohíbe a los Estados condicionar la indemnización de los daños y perjuicios causados a la declaración de la ilegalidad de la actuación dañosa, cuando la declaración de ilegalidad

92 STS (Sala de lo Cont.-Admvo., Secc. 4. ${ }^{\text {a) }}$, de 27 de octubre de 2004, rec. casación núm. 2029/2000.

93 STJUE de 9 de diciembre de 2010, C-568/08, As. Combinatie Spijker Infrabouw-De Jonge Konstruktie; Van Spijker Infrabouw $B V$, De Jonge Konstruktie BV y Provincie Denthe.

${ }^{94}$ En detalle, L. MEDINA ALCOZ (2007: 64 y ss.).

95 R. CARANTA (2011: 176).

96 Al respecto, S. DÍEZ SASTRE (2012: 258 y ss.).

97 STJUE de 30 de septiembre de 2010, C-314/09, As. Stadt Graz y Strabag AG, Teerag-Asgad AG, Bauunternehmung Granit GesmbH. S. DÍEZ SASTRE (2012: 266-267).

98 STJUE de 14 de octubre de 2004, C-275/03, As. Comisión c. República Portuguesa. 
se somete a un plazo de preclusión que comienza a computarse con independencia del conocimiento de la ilegalidad por parte del afectado. De un modo similar a la prohibición de la culpa, se entiende que esa normativa nacional vulnera el principio de efectividad, en la medida en que la declaración de ilegalidad se somete a un plazo más corto que la acción indemnizatoria. Se deduce, por tanto, que esos casos una exigencia de ese tipo constituye un obstáculo que puede dificultar o hacer imposible obtener una indemnización por daños y perjuicios ${ }^{99}$.

\subsection{Los daños causados al contratista}

Por lo que respecta al deber resarcitorio de la Administración frente al contratista, hay que tener en cuenta que la indemnización estará orientada a reparar los gastos en que incurrió en la creencia de que seguiría ejecutando el contrato en el futuro y que devienen inútiles cuando debe liquidarse el contrato y adjudicarse a otro. Se trata de un daño a la confianza creada por la Administración en que podría ejecutarse el contrato conforme a se pactó en su día. Por esa razón, el concepto indemnizable son los daños a la confianza, el interés negativo ${ }^{100}$. Esos daños pueden incluir indemnizaciones a trabajadores contratados para la ejecución del contrato, gastos de mantenimiento de locales o de maquinaria, entre otros ${ }^{101}$. Ahora bien, en ningún caso incluirán una indemnización por los beneficios que se dejan de obtener con la ejecución del contrato, ya que el contratista no tenía derecho al contrato. Si se le indemnizara por este concepto, por el interés positivo, se le colocaría en una posición que no nunca le habría correspondido de haberse procedido a adjudicar el contrato de manera conforme a Derecho ${ }^{102}$.

Distintos serían los casos de resolución del contrato por causa imputable a la Administración o de rescate del contrato para proceder a la gestión directa del servicio. En esos supuestos, el contratista tenía derecho al contrato y se le despoja del mismo. De modo que habrá que indemnizarlo por los daños que se derivan de no poder continuar ejecutando el contrato. Eso incluiría el beneficio industrial derivado de la ejecución del contrato.

\section{PROBLEMAS PRÁCTICOS}

\section{Los pronunciamientos de imposible ejecución}

Como se ha visto, la declaración de invalidez puede llevar aparejados múltiples efectos dirigidos a restablecer la legalidad o resarcir los daños ocasionados. El problema está en que el momento en que se predican esos efectos del acto inválido suele tener lugar años después de la producción del acto. Así sucede con carácter general en la jurisprudencia contencioso-administrativa. En 2017 la duración media para resolver un proceso en primera instancia ha superado los dos años, a pesar de que los tiempos de resolución han mejorado, en general, en las últimas décadas ${ }^{103}$. En la mayor parte de estos supuestos el mero transcurso del tiempo ha hecho imposible trasladar a la realidad los efectos de la invalidez. Dicho de otro modo, no se han podido ejecutar las medidas conducentes al restablecimiento de la legalidad ${ }^{104}$. En muchos casos el contrato ya está ejecutado, de modo que la condena a adjudicar el contrato a un tercero es de imposible ejecución. E incluso cuando el contrato está ejecutándose se plantea la duda sobre la conveniencia de anular el contrato y adjudicar el contrato a un tercero cuando puedan derivarse perjuicios importantes para el interés público ${ }^{105}$.

Así sucede, por ejemplo, cuando se adjudica un contrato de transporte escolar en septiembre de 2013 y se ordena la retroacción de actuaciones en $2015^{106}$; cuando en 2004 se licita conjuntamente la redacción de un proyecto de obra y su ejecución y se ordena la retroacción

99 STJUE de 26 de noviembre de 2015, C-166/14, As. MedEval - Qualitäts-, Leistungs- und Struktur-Evaluierung im Gesundheitswesen $\mathrm{GmbH}$.

100 V. S. BACA ONETO, La invalidez..., cit., pág. 371 y ss.

101 V. AGUADO I CUDOLÀ, "Efectos de...", cit., pág. 246.

102 V. S. BACA ONETO, La invalidez..., cit., pág. 373.

103 S. DÍEZ SASTRE (2018b: 141).

104 R. GÓMEZ-FERRER RINCÓN (2008: 192 y ss.).

105 Al respecto, S. GONZÁLEZ-VARAS IBÁÑEZ (2003: 133 y ss.).

106 STS (Sala de lo Cont.-Admvo., Secc. 4. ${ }^{\text {a) }}$, de 4 de octubre de 2016, rec. casación núm. 2903/2015 
de actuaciones para licitar separadamente ambas actuaciones en 2008 ${ }^{107}$; cuando se ordena retrotraer actuaciones para permitir la subsanación de un defecto en el aval bancario presentado por un licitador 3 años y 5 meses después de que se adjudicara un contrato de obras ${ }^{108}$; y cuando en 1998 se excluye ilegalmente a un licitador y en 2005, en casación, se ordena la retroacción de actuaciones ${ }^{109}$.

Solo en los casos en que se produjo una declaración de desierto del contrato una cancelación del procedimiento que después se considera contraria a derecho es posible retrotraer el procedimiento y asegurar que quien presentó la oferta económicamente más ventajosa sea quien ejecute el contrato ${ }^{110}$. En el resto de supuestos será común que en sede de ejecución de sentencias se compruebe que ya no es posible hacer efectivo el mandato de retrotraer las actuaciones. Lo que conducirá, en su caso, a indemnizar al interesado por la parte en que la sentencia no pueda ser objeto de cumplimiento pleno (art. 105.2 LJCA).

A la larga duración de los procesos se añade que en la jurisprudencia existe el convencimiento de que, en este tipo de supuestos, relativos al ejercicio de una actividad económica, no existen perjuicios de imposible reparación, de modo que no es habitual que se adopten medidas cautelares. Los jueces consideran que se trata de la adjudicación de una oferta contractual de contenido económico que siempre podrá repararse mediante una indemnización por daños y perjuicios ${ }^{111}$. Es más, llega a afirmarse expresamente que «no se deduce ninguna razón por la cual deban suspenderse unas obras públicas que en caso de prosperar el recurso daría lugar a una indemnización, determinada solamente en principio por el beneficio dejado de percibir por la demandante, sin que con ello se pudiera causar otro perjuicio al interés público» ${ }^{112}$. El resultado de esta interpretación es la imposibilidad, en la inmensa mayoría de los casos, de ejecutar una resolución dirigida a anular el acto y reponer el estado de cosas previo a la ilegalidad cometida. Únicamente pueden encontrarse supuestos en la jurisprudencia en los que con carácter excepcional se adoptan medidas cautelares, normalmente, de suspensión de la ejecución del contrato cuyos actos de preparación o adjudicación han sido objeto de recurso.

Así sucede, por ejemplo, cuando se impugna un contrato de gestión de servicio público de atención sanitaria especializada, debido a la posible pérdida de puestos de trabajo que supondría la ejecución del contrato ${ }^{113}$.

De estos datos puede deducirse claramente que la derivación de unos efectos u otros de la declaración de invalidez no es algo casual aleatorio, que depende de las circunstancias del caso. Está estrechamente ligada con el diseño las vías de reacción frente a la invalidez. El buen funcionamiento, rápido y eficaz, de la vía de reacción frente a la ilegalidad, va a determinar unos efectos u otros. Esta relación entre los efectos de la invalidez y las vías de reacción proviene del Derecho europeo. Las razones por las que en unos supuestos la invalidez lleva aparejada en la realidad el restablecimiento de la legalidad y en otros solo conlleva una indemnización no son circunstanciales. Tampoco dependen del tipo del vicio de invalidez (nulidad o anulabilidad) en que se haya incurrido.

La práctica común de los Estados miembros mostraba que, una vez celebrado el contrato, difícilmente podría restablecerse la legalidad. Esto se explicaba por la tradición jurídica de algunos países, que niega con carácter general la transmisibilidad de los vicios del procedimiento de adjudicación al contrato ${ }^{114}$. Pero también por la consolidación progresiva de intereses en juego que pugnan con el interés en el restablecimiento de la legalidad vulnerada por un acto inválido: es el caso del interés de la Administración en obtener la prestación y el interés del contratista en llevar a término la ejecución del contrato. En ese escenario la necesaria ponderación de todos los intereses en juego puede llevar a primar otros intereses distintos del interés en

107 STS (Sala de lo Cont.-Admvo., Secc. 7. a), de 17 de octubre de 2011, rec. casación núm. 2172/2009.

108 SAN (Sala de lo Cont.-Admvo., Secc. 8. ${ }^{\text {a) }}$, de 3 de marzo de 2010, rec. cont.-admvo. núm. 32/2007.

109 STS (Sala de lo Cont.-Admvo., Secc. 4. ${ }^{a}$ ), de 13 de julio de 2005, rec. casación núm. no disponible (RJI200519213).

110 STS (Sala de lo Cont.-Admvo., Secc. 4. ${ }^{a}$ ), de 4 de julio de 2007, rec. casación núm. 11256/2004.

111 ATS (Sala de lo Cont.-Admvo.), de 17 de mayo de 1985, rec. apelación núm. no disponible, RJ1985I2922; ATSJ de Cataluña (Sala de lo Cont.-Admvo., Secc. 5. ${ }^{a}$ ), de 15 de mayo de 2013, rec. cont.-admvo. núm. 27/2013; ATS (Sala de lo Cont.-Admvo., Secc. ${ }^{a}{ }^{a}$ ), de 3 de septiembre de 1995, rec. núm. 9655/1991; ATS (Sala de lo Cont.-Admvo., Secc. $4 .{ }^{a}$ ), de 18 de junio de 1992 , rec. núm. 11929/1990; ATS (Sala de lo Cont.-Admvo., Secc. 5. ${ }^{a}$ ), de 2 de enero de 1992, rec. núm. 6587/1990.

112 ATS (Sala de lo Cont.-Admvo., Secc. 4. ${ }^{\text {a) }}$, de 18 de noviembre 1991, rec. núm. 6125/1990.

113 AATSJ de Madrid (Sala de lo Cont.-Admvo., Secc. 3. ${ }^{a}$ ), de 27 de enero de 2014, medidas cautelares núms. 965/2013, 787/2013 y $933 / 2013$

114 S. DÍEZ SASTRE (2012: 120). 
restaurar la situación previa a la comisión de la ilegalidad. Se produce una tensión constante entre seguridad jurídica y legalidad ${ }^{115}$. De hecho, el derecho europeo reconoce abiertamente que antes de la celebración del contrato los efectos de la invalidez serán el restablecimiento de la legalidad y la indemnización por daños y perjuicios, pero que, después de ese momento, es posible reducir esos efectos a la indemnización (art. 2.6 2. ${ }^{\circ}$ párr. Directiva 89/665/CEE). Es consciente de la dificultad existente en la realidad para derivar efectos restitutorios de un acto inválido.

El factor clave que determina que de un acto inválido se prediquen unos actos u otros no depende, por tanto, de la calificación teórica del tipo de ilegalidad cometida, sino, fundamentalmente, del transcurso del tiempo, que conduce a la firma del contrato. A diferencia del juicio de validez que es un juicio estático de la realidad y la norma vulnerada, el juicio de eficacia es un juicio dinámico que obliga a tomar en cuenta todos los intereses y derechos afectados. Por eso, hay una fase en la que «las infracciones aún pueden corregirse» (Cdo. 2. ${ }^{\circ}$ Directiva 89/665/CEE), más allá de la cual esa misión se dificulta considerablemente por el simple devenir de los hechos. Esto explica por qué el derecho europeo pone el énfasis en la regulación del procedimiento de adjudicación (plazo de espera entre adjudicación y notificación, así como notificación a todos los afectados de la adjudicación con los motivos que la justifican- y de los procedimientos posteriores plazos breves de interposición, efecto suspensivo automático del recurso cuando se recurre la adjudicación, medidas provisionales autónomas, antes del recurso, y resolución por un órgano imparcial- de recurso de modo que abran espacios temporales suficientes y adecuados para evitar la firma del contrato y, sobre todo, para garantizar que un posible recurso se resuelve de forma rápida y eficaz -entendiendo por eficaz, que el sentido de la resolución que ponga fin al recurso pueda ser objeto de ejecución en los términos que ella misma establezca-. Ahora bien, también hay que tener en cuenta a qué supuestos conviene extender estas vías de recurso que, son más rápidas y eficaces, pero también más costosas.

\section{La falta de capacidad directiva de la conducta administrativa}

Junto a los problemas planteados, hay que analizar los efectos típicos de la invalidez desde el punto de vista de su capacidad de dirección de la actuación administrativa. Las consecuencias derivadas de la declaración de invalidez de un acto deberían constituir un desincentivo para que la Administración cometa ilegalidades en el futuro. De hecho, un argumento a favor de mantener el concepto clásico de invalidez, entendido como desajuste de la realidad con el derecho, es precisamente el juicio de reproche que conlleva. Se entiende que una declaración de nulidad es algo similar a una sanción ${ }^{116}$. Si se ha dictado un acto nulo, con independencia de que se hayan mantenido sus efectos, la Administración debería recibir un mensaje claro de que su actuación no puede desarrollarse de ese modo.

Sin embargo, el elevado número de estimaciones en el contencioso-administrativo (superior al $40 \%$ de media en 2017) pone de manifiesto que la actuación administrativa debe continuar mejorando ${ }^{117}$. Tal vez las declaraciones de invalidez cumplen una función pedagógica en la medida en que muestran a la comunidad jurídica lo que queda fuera del derecho. Pero a efectos prácticos, la mera declaración de nulidad no parece ser un mecanismo suficientemente persuasivo para que la Administración modifique su conducta. Tampoco la obligación de tramitar de nuevo ciertas fases del procedimiento subsanando los defectos identificados parece tener ninguna trascendencia cuando no hay posibilidad de afectar al sentido de la resolución de adjudicación y, por tanto, no cabe ningún tipo de sanción «directa» o «indirecta» a la actuación administrativa. Una mera carga de repetición de trámites no puede considerarse un incentivo para que la Administración evite actuaciones inválidas. Lo mismo sucede con el deber de adjudicar el contrato a un licitador determinado, obligando a liquidar el contrato ya celebrado, o con la cancelación de la licitación. En muy pocos casos llegan a ejecutarse fallos de este tipo. En resumen, la capacidad de dirección de la configuración de los efectos de la invalidez en la actualidad es, por tanto, cuestionable.

En esta clave, el derecho europeo aporta otra perspectiva de interés, que se ha apuntado más arriba al referirse a las consecuencias derivadas del mantenimiento de los efectos del contrato. Consiste en entender la invalidez como la constatación de una infracción que debe ser "sancionada» ${ }^{118}$. Desde esta perspectiva el juicio sobre los efectos de la invalidez no puede consistir únicamente en una ponderación de

\footnotetext{
115 M. BELADIEZ ROJO (1994: 263).

116 T. CANO CAMPOS (2017: 9-10).

117 S. DÍEZ SASTRE (2018b: 136).

118 También aparece esa perspectiva en M. BELADIEZ ROJO (1994: 53).
} 
los intereses en juego con el fin de tutelar las posiciones jurídicas de los sujetos afectados por una licitación y el interés general. Hay que atender a los resultados que esa ponderación tiene en la realidad y modularlos para garantizar que la invalidez no queda «impune». Esta visión se explica en la relación de tensión existente entre la Unión Europea y los Estados miembros a la hora de aplicar las normas de contratación pública europeas. Pero ofrece un punto de vista útil para aportar una visión más pragmática de la invalidez que atienda verdaderamente a los efectos que se producen en la realidad. Así sucede cuando prevé consecuencias alternativas que "castiguen» a la Administración cuando no es adecuado dejar sin efectos un contrato ya perfeccionado.

El derecho europeo no renuncia, por tanto, a dejar sin efectos en la realidad una declaración de invalidez cuando se ha llegado a celebrar un contrato vulnerando ciertas normas procedimentales. Si el restablecimiento de la legalidad no cabe, deben imponerse otras consecuencias. De modo que es posible ampliar el espectro de las consecuencias derivadas de la invalidez con la finalidad de lograr un verdadero "castigo» 0 reproche.

\section{CONCLUSIONES: EL DERECHO ES EFICAZ CUANDO SE APLICA A TIEMPO}

La introducción de los nuevos mecanismos de recurso en el ámbito precontractual y contractual ha producido un cambio radical en la determinación de los efectos de los actos inválidos. Los breves plazos de resolución de los recursos ${ }^{119}$, acompañados de la adopción de medidas provisionales -entre ellas, el efecto suspensivo obligatorio cuando el recurso impugna la adjudicación- permite el restablecimiento de la legalidad antes de la celebración del contrato, así como la indemnización, en su caso, de los daños y perjuicios ocasionados. Esto supone un cambio del acento del resarcimiento (tutela secundaria) al restablecimiento de la legalidad (tutela primaria), como efecto de la invalidez ${ }^{120}$. Además, de esta manera se produce un efecto verdaderamente disuasorio de las declaraciones de invalidez. Se conoce la certeza de los efectos que pueden producirse: paralización o cancelación de las licitaciones, retroacción de actuaciones y obligación de adjudicar el contrato a un licitador determinado. Además, se crea un cuerpo de doctrina que ayuda a la interpretación de una normativa compleja y cambiante.

Los efectos deseables vinculados al verdadero restablecimiento de la legalidad solo se producen cuando se reacciona con rapidez frente a la misma. De este modo se generan mecanismos que desincentivan la comisión de ilegalidades y que, al mismo tiempo, pueden ser eficaces para evitar las prácticas corruptas en el ámbito de la contratación pública ${ }^{121}$. En resumen, puede decirse que la contratación pública nos da un ejemplo de que la configuración del procedimiento de adjudicación en consonancia con los procedimientos de recursos introducidos de la mano del derecho europeo son la prueba de que "[e]l Derecho solo es eficaz cuando se aplica a tiempo» ${ }^{122}$.

\section{BIBLIOGRAFÍA}

AGUADO I CUDOLÀ, VICENÇ (2017): "Efectos de la invalidez y prórroga de los contratos públicos", en FERNANDO LÓPEZ RAMÓN y FRANCISCO VILLAR ROJAS (coords.), El alcance de la invalidez de la actuación administrativa, Madrid: INAP, págs. 223-272.

ALONSO IBÁÑEZ, MARÍA ROSARIO (2017): "Régimen general de la invalidez de los actos administrativos y sus efectos", en LÓPEZ RAMÓN, FERNANDO y VILLAR ROJAS, FRANCISCO (coords.), El alcance de la invalidez de la actuación administrativa, Madrid: INAP, págs. 23-56.

AYMERICH CANO, CARLOS (2015): Un problema pendiente: la anulación de los contratos administrativos afectados por actos de corrupción, Cizur Menor: Thomson-Reuters, Aranzadi.

ARROYO, LUIS Y UTRILLA, DOLORES (dirs.) (2015): La administración de la escasez. Los fundamentos de la actividad administrativa de adjudicación de derechos limitados en número, Madrid: Marcial Pons.

BACA ONETO, VÍCTOR SEBASTIÁN (2006): La invalidez de los contratos públicos, Cizur Menor: Thomson-Civitas.

BACIGALUPO SAGGESE, MARIANO (1997): La discrecionalidad administrativa (estructura normativa, control judicial y límites constitucionales de su atribución), Madrid: Marcial Pons.

\footnotetext{
119 Al respecto, S. DÍEZ SASTRE (2018b: 119).

120 F. WOLLENSCHLÄGER (2010: 263).

121 J. M. ${ }^{a}$ GIMENO FELIÚ (2011: 196 y ss.).

122 E. SCHMIDT-AßMANN (2003: 69).
} 
BAÑO LEÓN, JOSÉ MARÍA (2004): "El contencioso precontractual: las insuficiencias de la tutela jurisdiccional", en GÓMEZ-FERRER MORANT, R. (dir.), Comentario a la Ley de Contratos de las Administraciones Públicas, $2 .^{a}$ ed., Cizur Menor: Thomson-Civitas, págs. 329-363.

BAÑO LEÓN, JOSÉ MARÍA (2011): "La retroacción de actuaciones ¿denegación de justicia o garantía del justiciable?", en REDA, núm. 152, págs. 839-857.

BELADIEZ ROJO, MARGARITA (1994): Validez y eficacia de los actos administrativos, Madrid: Marcial Pons.

BOCANEGRA SIERRA, RAÚL (2011): "La distinción entre la eficacia interna y la eficacia externa de los actos administrativos", en REDA, núm. 152, págs. 769-786.

CANO CAMPOS, TOMÁS (2004): La invalidez sobrevenida de los actos administrativos, Madrid: Thomson-Civitas.

CANO CAMPOS, TOMÁS (2012): "La imposibilidad de retrotraer actuaciones cuando se vulneran los derechos fundamentales en el procedimiento administrativo sancionador (A propósito de las sentencias de la Audiencia Nacional, de 27 de mayo de 2009, y del Tribunal Superior de Justicia de Valencia, de 17 de junio de 2010)", en GARCÍA DE ENTERRÍA, E. y ALONSO GARCÍA, R. (coords.), Administración y Justicia. Un análisis jurisprudencial, Volumen I. España, Liber Amicorum Tomás-Ramón Fernández, Cizur Menor: Civitas, ThomsonReuters, págs. 841-866.

CANO CAMPOS, TOMÁS (2017): "El laberinto de la invalidez: algunas pistas para no perderse", Ponencia en el XII Congreso de la AEPDA, págs. 1-54.

CARANTA, ROBERTO (2011): "Damages: Causation and Recoverable Losses", en FAIRGRIEVE, D. y LICHÈRE, F. (eds.), Public Procurement Law. Damages as an Effective Remedy, Croydon: Hart Publishing, págs. $167-184$. DOI: 10.5040/9781472561046.ch-009.

DE CASTRO Y BRAVO, FEDERICO (1985): El negocio jurídico, Madrid: Civitas.

DÍEZ SASTRE, SILVIA (2012): La tutela de los licitadores en la adjudicación de contratos públicos, Madrid: Marcial Pons.

DÍEZ SASTRE, SILVIA (2017): "Los efectos de la invalidez en los procedimientos de adjudicación de contratos públicos", en LÓPEZ RAMÓN, FERNANDO y VILLAR ROJAS, FRANCISCO (coords.), El alcance de la invalidez de la actuación administrativa, Madrid: INAP, págs. 273-318.

DÍEZ SASTRE, SILVIA (2018a): La formación de conceptos en el Derecho público, Madrid: Marcial Pons.

DÍEZ SASTRE, SILVIA (2018b): "Análisis de la litigiosidad administrativa y contencioso-administrativa en materia de contratación pública”, en DÍEZ SASTRE, S. (dir.), Informe sobre la Justicia Administrativa 2018 (Tributos, Contratos Públicos, Responsabilidad Patrimonial, Derechos Fundamentales, Personal de la Administración, Protección de Datos y Transparencia), Madrid: Centro de Investigación sobre Justicia Administrativa de la Universidad Autónoma de Madrid, CGPJ, CEPC, págs. 101-145. Disponible on line: http://cija-uam.org/wp-content/ uploads/2018/09/Informe_CIJA_2018FINAL.pdf.

DÍEZ SASTRE, SILVIA (2018c): “La invalidez de los contratos públicos”, en GIMENO FELIÚ, JOSÉ MARÍA (dir.), Estudio sistemático de la Ley de Contratos del Sector Público, Cizur Menor: Thomson Reuters-Aranzadi, págs. 571-597.

DOMÉNECH PASCUAL, GABRIEL (2002): La invalidez de los reglamentos, Valencia: Tirant lo Blanch.

DOMÉNECH PASCUAL, GABRIEL (2010): "El principio de presunción de validez", en SANTAMARÍA PASTOR, J. A. (dir.), Los principios jurídicos del derecho administrativo, Alcobendas: La Ley, págs. 1.031-1.060.

FERNÁNDEZ-RODRÍGUEZ, TOMÁS RAMÓN (1969): "Los vicios de orden público y la teoría de las nulidades en el Derecho administrativo", en $R A P$, núm. 58, págs. 49-126.

GALLEGO ANABITARTE, ALFREDO y MENÉNDEZ REXACH, ÁNGEL (2001): Acto y procedimiento administrativo, Madrid: Marcial Pons.

GALLEGO CÓRCOLES, MARÍA ISABEL (2011): "Contratos públicos y régimen «cualificado» de invalidez: supuestos especiales y cuestión de nulidad”, en GIMENO FELIÚ, J. M. a (dir.), Observatorio de Contratos Públicos 2010, Cizur Menor: Civitas, Thomson-Reuters, págs. 259-318.

GALLEGO CÓRCOLES, MARÍA ISABEL (2012): "Observatorio de jurisprudencia en materia de contratos públicos", en J. M. a GIMENO FELIÚ (dir.), Observatorio de Contratos Públicos 2011, Cizur Menor: Civitas, ThomsonReuters, págs. 133-178.

GARCÍA ÁLVAREZ, GERARDO (2018): "Invalidez del contrato público”, en GAMERO CASADO, EDUARDO y GALLEGO CÓRCOLES, MARÍA ISABEL (dirs.), Tratado de Contratos del Sector Público, Tomo I, Valencia: Tirant lo Blanc, págs. 801-834.

GARCÍA LUENGO, JAVIER (2002): La nulidad de pleno derecho de los actos administrativos, Madrid: Civitas.

GIMENO FELIÚ, JOSÉ MARÍA (2011): "El nuevo sistema de recursos en materia de contratos públicos", en GIMENO FELIÚ, J. M. ${ }^{a}$ (dir.), Observatorio de Contratos Públicos 2010, Cizur Menor: Civitas, Thomson-Reuters, págs. 211258.

GONZÁLEZ-VARAS IBÁÑEZ, SANTIAGO (2003): El contrato administrativo, Madrid: Civitas.

GÓMEZ-FERRER RINCÓN, RAFAEL (2008): La imposibilidad de ejecución de sentencias en el proceso contenciosoadministrativo, Cizur Menor: Thomson-Civitas.

HUERGO LORA, ALEJANDRO (2000): Las pretensiones de condena en el contencioso-administrativo, Cizur Menor: Aranzadi. 
LETELIER WARTENBERG, RAÚL (2011): Nulidad y restablecimiento en procesos contra normas, Cizur Menor: Civitas, Thomson-Reuters.

MALAVIYA, NINA (2009): Verteilungsentscheidung und Verteilungsverfahren, Tübingen: Mohr Siebeck.

MCCORMICK, NEIL (2011): Instituciones del Derecho, Madrid: Marcial Pons.

MEDINA ALCOZ, LUIS (2005): La responsabilidad patrimonial por acto administrativo. Aproximación a los efectos resarcitorios de la ilegalidad, la morosidad y la deslealtad desde una revisión general del sistema, Madrid: Thomson-Civitas.

MEDINA ALCOZ, LUIS (2007): La teoría de la pérdida de oportunidad. Estudio doctrinal y jurisprudencial de Derecho de daños público y privado, Cizur Menor: Thomson-Civitas.

MORENO MOLINA, JOSÉ ANTONIO (2010): La reforma de la Ley de Contratos del Sector Público en materia de recursos. Análisis de la Ley 34/2010, de 5 de agosto, Getafe: La Ley.

MOREO MARROIG, T. (2015): "Reconocimiento extrajudicial de crédito. El artículo 60.2 del Decreto 500/1990, de 20 de abril, ¿bálsamo de Fierabrás de la contratación irregular?”, disponible online en www.administracionpublica. com.

NIETO, ALEJANDRO (1994): "Estudio preliminar", en Beladíez Rojo, M., Validez y Eficacia de los Actos Administrativos, Madrid: Marcial Pons, págs. 9-31.

PÉREZ TRIVIÑO, JOSÉ LUIS (1999): "Validez, aplicabilidad y nulidad. Un análisis comparativo de la teoría del Derecho y la dogmática jurídica”, en Doxa, núm. 22, págs. 263-283. DOI: 10.14198/doxa1999.22.10.

REBOLLO PUIG, MANUEL (1994): El enriquecimiento injusto de la Administración pública, Madrid: Marcial Pons.

REBOLLO PUIG, MANUEL (2009): "La nulidad en Derecho Administrativo (Consideración de su significado y régimen en el actual Derecho Administrativo español a propósito de la nulidad de los derechos fundamentales)", en Justicia Administrativa, núm. 44, págs. 5-39.

RODRÍGUEZ-ARANA, JAIME (1988): La prórroga en los contratos administrativos. Concepto, funcionalidad y régimen en los contratos de obras y en los de gestión de servicios públicos, Madrid: Montecorvo.

RODRÍGUEZ FERNÁNDEZ, IGNACIO (2009): Demolición por delito. El restablecimiento de la legalidad urbanística en la vía penal, Granada: Comares.

RODRÍGUEZ DE SANTIAGO, JOSÉ MARÍA (2016): Metodología del Derecho Administrativo. Reglas de racionalidad para la adopción y el control de la decisión administrativa, Madrid: Marcial Pons.

SANTAMARÍA PASTOR, JUAN ALFONSO (1975): La nulidad de pleno derecho de los actos administrativos, $2 .^{a}$ ed., Madrid: IEA.

SANTAMARÍA PASTOR, JUAN ALFONSO (2004): "La invalidez de los contratos públicos", en GÓMEZ-FERRER MORANT, R. (dir.), Comentarios a la Ley de Contratos de las Administraciones Públicas, 2. ${ }^{a}$ ed., Cizur Menor: Thomson-Civitas, págs. 365-396.

SCHMIDT-ABMANN, EBERHARD (2003): La Teoría General del Derecho Administrativo como Sistema, Madrid: Marcial Pons, INAP.

SCHNEIDER, TOBIAS (2007): Primärrechtsschutz nach Zuschlagerteilung bei einer Vergabe öffentlicher Aufträge. Der oberhalb der Schnwellenwerte bestehende vergaberechtliche Primärrechtsschutz des nichtberücksichtigten Bieters nach Zuschlagerteilung, Berlin: Duncker \& Humblot.

VALERO ESCRIBANO, J. I. (2015), "La regularización de las facturas derivadas de contrataciones irregulares", en Revista Española de Control Externo, vol. XVII, núm. 50, mayo 2015, pág. 163 y ss.

WOLLENSCHLÄGER, FERDINAND (2010): Verteilungsverfahren, Tübingen: Mohr Siebeck. DOI: 10.1628/978-3-16151277-3. 